\title{
Revising Growth Theory in the Artificial Age: Putty and Clay Labor
}

\author{
Julia M. Puaschunder \\ The New School, Department of Economics, \\ Schwartz Center for Economic Policy Analysis, \\ 6 East $16^{\text {th }}$ Street, $9^{\text {rd }}$ floor 89, New York, New York 10003, USA. \\ Columbia University, Graduate School of Arts and Sciences, \\ $116^{\text {th }}$ Street Broadway, New York, New York 10027, USA. \\ Princeton University, Graduate School of Arts and Sciences, \\ Princeton, New Jersey, USA.
}

Financial support of the Austrian Office of Science and Technology, a European Parliament Agency, Fritz Thyssen Foundation, Research Association for Interdisciplinary Studies, The New School (Dean's Office, Department of Economics, Fee Board, Social Science Fellowship, The New School for Social Research, The New School Eugene Lang College), Taylor \& Francis, University of Vienna and Vernon Arts and Science is gratefully acknowledged. The author thanks Professor Graciela Chichilnisky and Sofia Profita for most generous access to information and expertise. The author thanks Professor Martin Gelter for invaluable input for the panel regression. The author thanks Professor Benjamin Moll and Professor Richard Rogerson for most excellent lectures on 'Economic Development II' during Spring 2019, Patrick Agte and the other participants of the class for most helpful collegial support. The author declares no conflict of interest. All omissions, errors and misunderstandings in this piece are solely the author's.

\section{ABSTRACT}

The introduction of Artificial Intelligence (AI) in our contemporary society imposes historically unique challenges for humankind. The emerging autonomy of AI holds unique potentials of eternal life of robots, AI and algorithms alongside unprecedented economic superiority, data storage and computational advantages. Yet to this day, it remains unclear what impact AI taking over the workforce will have on economic growth. This paper therefore first establishes what AI is and provides a theoretical background on standard neoclassical and heterodox economics growth theories with particular attention to the Cambridge Capital Controversy's argument to divide capital components into fluid, hence more flexible (e.g., petty cash, checking account), and more clay, hence more inflexible (e.g., factories and intransferable means of production), components. The contemporary trend of slowbalisation is described, as the slowing down of conventional globalization of goods, services and Foreign Direct Investments (FDI) flows; yet at the same time, we still see human migration and air travel as well as data transfer continuing to rise. These market trends of conventional globalization slowing and rising AI-related industries are proposed as first market disruption in the wake of the large-scale entrance of AI into our contemporary economy. Growth in the artificial age is then proposed to be measured based on two AI entrance proxies of Global Connectivity Index and The State of the Mobile Internet Connectivity 2018 Index, which is found to be highly significantly positively correlated with the total inflow of migrants and FDI inflow - serving as evidence that the still globalizing rising industries in the age of slowbalisation are connected to AI. Both indices are positively correlated with GDP output in cross-sectional studies over the world. In order to clarify if the found effect is a sign of industrialization, time series of worldwide data reveal that internet connectivity around the world is associated with lower economic growth from around 2000 on until 2017. A regression plotting Internet Connectivity and GDP per capita as independent variables to explain the 
dependent variable GDP growth outlines that the effect for AI is a significant determinant of negative GDP growth prospects for the years from 2000 until 2017. A panel regression plotting GDP per capita and internet connectivity from the year 2000 to explain economic growth consolidates the finding that AI-internet connectivity is a significant determinant of negative growth over time for 161 countries of the world. Internet connectivity is associated with economic growth decline whereas GDP per capita has no significant relation with GDP growth. To cross-validate both findings hold for two different global connectivity measurements. The paper then discusses a theoretical argument of dividing labor components into fluid, hence more flexible (e.g., AI), and more clay, hence more inflexible (e.g., human labor), components. The paper ends on a call for revising growth theories and integrating AI components into growth theory. AI entrance into economic markets is modeled into the standard neoclassical growth theory by creating a novel index for representing growth in the artificial age comprised of GDP per capita and AI entrance measured by the proxy of Internet Access percent per country. Maps reveal the parts of the world that feature high GDP per capita and AI-connectivity. The discussion closes with a future outlook on the law and economics of AI entrance into our contemporary economies and society in order to aid a successful and humane introduction of AI into our world.

Keywords: AI, AI-GDP Index, AI market entry, Artificial Intelligence, capital, economic growth, endogenous growth, exogenous growth, Global Connectivity Index, GDP, Gross Domestic Product, labor, law and economics, society, State of the Mobile Internet Connectivity, workforce

\section{INTRODUCTION}

Artificial Intelligence (AI) as intelligence demonstrated by machines, in contrast to the natural intelligence displayed by humans and other animals, poses historically unique challenges on humankind. Contemporary economists estimate the introduction of AI and algorithms into the workforce to be the disruption of the world economy and global society of the millennium. As emerging globally trend, $\mathrm{AI}$ is extending its presence at almost all levels of human conduct and thereby raising both - expectations and concerns (Cellan-Jones, 2014; Sofge, 2015; United Nations, 2017). But what the AI revolution will concretely mean for internal economies and their growth prospects, we hardly have any economic information about.

Standard economic growth is captured in growth theories, which are underlying economic development studies (Deaton, 2010; Kuznets, 1973). The history of growth theories features aggregate production function calculus as the extension of the micro-economic production function at a national or economy-wide level. The aggregate production function describes the relationship of the size of an economy's labor force and its capital stock with the level of the country's Gross National Product (GNP). The value of output or national product is thereby captured by the value of the aggregate capital stock and labor force (Jones, 2014). Aggregate production is explained by how capital and labor of an economy contribute to growth (Jones, 1999). Capital stock is usually improved through new investments and decreased by depreciation. Labor supply is determined by the change in labor force, for instance through population growth or education.

Growth theory had originally been focused on exogenous growth foremost pioneered in the work of Robert Solow's Growth Model (1956). Solow's growth theory was based on the two factors capital (K) and labor (L), which are argued to drive every economy (Solow, 1956). Derivations include technology into the model insofar as output per effective worker becomes a function of capital per effective worker, whereby international differences are prevalent (Bartelsman, Haltiwanger \& Scarpetta, 2013; Comin \& Hobijn, 2004, 2010). Later Paul Romer integrated the idea of endogenous growth theory into development economics based on ideas, learning and research and development as drivers of innovation (Bils \& Klenow, 2002; Lucas, 1988, 1999). 
With AI entering the workforce, first we need to understand if these innovations will influence capital or labor. It may be the case that capital will drive out labor - for instance if robots are considered as investment in infrastructure that makes human capital unnecessary (Erosa, Koreshkova \& Restuccia, 2010). Following a tradition of endogenous growth models, labor needs to be revised into AI components and human labor force (Aghion, Jones \& Jones, 2017).

The paper proposes to investigate the economic impact of AI on economic growth and introduce AI-related theoretical modifications of capital and labor components of standard growth theory (Acemoglu, 2009a, b; Jones \& Olken, 2008). The article argues that AI should become integrated into capital and labor elements of growth theory and that we need a new understanding of labor in the artificial age. For this distinction, the historic Cambridge Capital Controversy may hold valuable inputs how to theoretically determine different parts of labor. The historic Cambridge Capital Controversy, in which two types of capital, putty and clay capital nuances were introduced to standard neoclassical growth theories, allows inferences to the contemporary labor force transition in the wake of AI entering. We need to define labor elements that are based on AI, which are introduced as putty labor (hence fungible and eternal), and human labor elements, which are more clay (hence inflexible and less fungible) than putty. These theoretical insights will be discussed as for social, economic and legal implications to society and democracy in the artificial age. The discussion will also argue that inequality stemming from the gap between skilled and unskilled labor is believed to increase with AI entering the workforce and contemporary reshoring trends in the wake of the slowing of traditional globalization (Piketty, 1997).

The paper is structured as follows: First, the concept of AI is described and the impact of AI on the contemporary workforce and society. Slowbalisation, or the slowing of conventional globalization measures, is introduced - for the very first time - as potential first market disruption effect of AI entering our contemporary workforce if considering that all AI-related industries still seem to growth exponentially. Then, standard growth theories of Robert Solow and Paul Romer as well as augmentions will be presented. The theoretical part closes with an introduction of the historical Cambridge Capital Controversy, which argued for attention to putty (hence flexible and fluid) and clay (hence fixed and bound) parts of capital. The slowbalisation trend is empirically validated. Growth in the artificial age is then measured empirically based on two AI entrance proxies of Global Connectivity Index and The State of the Mobile Internet Connectivity 2018 Index, which are both positively correlated with GDP in cross-sectional studies over the world. Time series of worldwide data reveal that internet connectivity around the world is associated with lower economic growth though. Accounting for per capita differences; a regression plotting Internet Connectivity and GDP per capita as independent variables to explain the dependent variable GDP growth outlines that the effect for AI is a significant determinant of negative GDP growth prospects for the years from 2000 until 2017 (Caselli, 2005). The discussion of the theoretical part calls for attention to revise growth theory and integrate AI as well as defining putty and clay aspects of labor in the artificial age. A novel index of AI-attentive growth theories is proposed for the very first time. Future implications of AI entering tomorrow's workforce in regards to inequality stemming from skilled and unskilled-job payments are discussed and a future societal, economic and legal outlook of AI entering our markets, democracies and society is given (Harberger, 1998; Pritchett, 1997).

\section{Artificial Intelligence (AI)}

\section{THEORY}

Artificial Intelligence (AI) is "a broad set of methods, algorithms, and technologies that make software 'smart' in a way that may seem human-like to an outside observer" (Noyes, 2016). 
The "human-like" intelligence of machines derives from machines being created to think like humans but at the same time to also act rationally (Laton, 2016; Russell \& Norvig 1995; Themistoklis, 2018). AI is perceived as innovative technology or as the sum of different technological advances as the privilege of the private, technological sector with little - if any public regulation (Dowell, 2018).

As the most novel trend, AI, robots and algorithms are believed to soon enter the economy and completely disrupt employment patterns. With the advancement of technologies, employment patterns will shift to a polarization between Al's rationality and humanness. Robots and social machines have already replaced people in a variety of jobs - e.g. airports smart flight check-in kiosks or self-check-outs instead of traditional cashiers. Almost all traditional professional are prospected to be infused with or influenced by AI, algorithms and robotics. For instance, robots have already begun to serve in the medical and health care profession, law and - of course - IT, transportation, retail, logistics and finance, to name a few (Puaschunder, work in progress). Social robotics may also be quasi-servants that overwhelmingly affect our relationships. Already now social robots are beginning to take care of our elderly and children, and some studies are currently underway on the effects of such care but also on the ethical boundaries of a such attempt (Alemi, Meghdari \& Saffari, 2017; Puaschunder, work in progress). Not only will AI and robots offer luxuries of affordability and democratization of access to services, as they will be - on the long run - commercially more affordable and readily available to serve all humanity; but also does the longevity potential of machines outperform any human ever having lived (Hayes, 2018). However, the new technology also comes with the price of overpopulation problems and the potential for misuse and violent action (Puaschunder, work in progress). Just like many other technologies, robots could be misused for wars, terrorism, violence and oppression (Alemi et al., 2017; Puaschunder, 2018a).

AI's entrance in society will revolutionize the interaction between humans and AI with amply legal, moral and social implications (Kowert, 2017; Larson, 2010). Autonomous AI entities are currently on the way to become as legal quasi-human beings, hence self-rule autonomous entities (Themistoklis, 2018). AI is in principle distinguished between weak AI, where "the computer is merely an instrument for investigating cognitive processes" and strong AI, where " $[t]$ he processes in the computer are intellectual, self-learning processes" (Wisskirchen, Biacabe, Bormann, Muntz, Niehaus, Jiménez Soler \& von Brauchitsch, 2017, p. 10). Weak AI is labeled as Artificial Narrow Intelligence (ANI) while strong AI is further classified into Artificial General Intelligence (AGI) and Artificial Super Intelligence (ASI).

The emergence of robotics technology is developing much quicker than previously thought. Robots are anticipated to soon be as ubiquitous as computers are today (Meghdari \& Alemi, 2018). Society has long been concerned with the impact of robotics technology from nearly a century ago, when the word "Robot" was devised for the first time (Căpek, 1921/2004; Meghdari \& Alemi, 2018). The EU Committee on Legal Affairs (2016, p. 4) holds that "[U]ltimately there is a possibility that within the space of a few decades AI could surpass human intellectual capacity in a manner which, if not prepared for, could pose a challenge to humanity's capacity to control its own creation and, consequently, perhaps also to its capacity to be in charge of its own destiny and to ensure the survival of the species." AI mimicking human intellect could soon surpass humans intellectually but also holistically breaking the barrier of human controlled-automization (Schuller, 2017; Themistoklis, 2018). Modern literature about robots features cautionary accounts about insufficient programming, evolving behavior, errors, and other issues that make robots unpredictable and potentially risky or dangerous (Asimov, 1942/1950, 1978, 1985; Meghdari \& Alemi, 2018). "Observe, orient, decide, act" will therefore become essential in the eye of machine learning autonomy and AI 
forming a new domain of intellectual entities (Armstrong \& Sotala, 2012, p. 52; Copeland, 2000; Galeon \& Reedy, 2017; Marra \& McNeil, 2013). The uncertainty surrounding AI development and self-learning capabilities give rise to the need for guarding AI and an extension of the current legal system to cope with AI (Themistoklis, 2018; Puaschunder, 2018a).

With the advancement of technology, social robots have found broader applications in the private and public sectors, such as educational and cultural affairs, games and entertainment, clinical and rehabilitation, nursing of children and/or elderly, search and rescue operations (Meghdari, Alemi, Zakipour \& Kashanian, 2018). For example, social robots - such as ASIMO, Nao, iCub, ARASH, and RASA - have been developed for "Edutainment" or "educationentertainment" purposes. They aid the study of cognition (both human and artificial), motion, and other areas related to the advancement of robotics serving our society (Meghdari \& Alemi, 2018). In addition, a few medical and healthcare toy-like robots, such as PARO, which looks like a baby seal, or ARASH, which is a humanoid, have been designed for therapeutic purposes such as reducing distress, stimulating cognitive activity, teaching specific subjects, and improving socialization (Meghdari, Shariati, Alemi \& Vossoughi, 2018). Similarly, Sharif University of Technology's socially assistive robot RASA has been developed to help coach and teach Persian Sign-Language to Iranian deaf children (Meghdari et al., 2018). Personal care and companion robots are increasingly being used to care for the elderly and children, such as RI-MAN, PaPeRo, and CareBot (Meghdari \& Alemi, 2018; Puaschunder, 2018b).

In recent years, robotics technology has extended its applications from factories to more general-purpose practices in society - for instance, such as the use of robots in clinical and rehabilitation, nursing and elderly care, search and rescue operations (Meghdari \& Alemi, 2018). Social robots have become clinical and educational assistants for social interventions, treatment, and education such as language trainings but also assistance with children with disabilities like autism, down syndrome, cancer distress, hearing impairment, etc. (Taheri, Meghdari, Alemi \& Pouretemad, 2018; Meghdari et al., 2018). Initial investigations clearly indicate that social robots can play a positive role in the improvement of children's social performance, reduction of distress during treatments, and enhancing their learning abilities (Meghdari \& Alemi, 2018). Surprisingly, although not too hard to imagine, relationships of a more intimate nature have not quite been satisfied by robots yet (Meghdari et al., 2018; Veruggio, 2005).

\section{Artificial Intelligence (AI) entering markets}

Already now, about 28 percent of the workforce in modern economies are estimated to be based on AI or AI-supported (Fraad-Wolff, in speech). First market disruptions of AI entering economies are currently speculated to cause a trend of slowbalisation - as a counter-trend to globalization. Globalization sprang from America's sponsorship of a new world order in 1945, which allowed cross-border flows of goods and capital to recover after years of war and chaos (Centeno, Creager, Elga, Felton, Katz, Massey \& Shapiro, 2013; Centeno, \& Tham, 2012). During the golden age of globalization from 1990-2010 the world became flat: Immigration increased from 2.9 to 3.3 percent of the world's population and global trade grew from 39 percent of GDP in 1990 to 58 percent last year (The Economist, January 26, 2019). Asia became part of the globalized upon China's entry into the WTO in 2001, which created a model of offshoring manufacturing to countries based on cost efficiency variances, primarily labor costs (Profita, 2019). The Washington Consensus embraced the world and promised to bring prosperity to everyone around the globe (Rodrik, 2006). Open markets and free trade were praised to lift billions of people out of poverty in Asia, Latin America and Africa via economic growth (Held \& McGrew, 2007). 
With the collapse of the Soviet Union in 1989 and the end of the Cold War in 1991, the world became even more interconnected and global market economies integrated around the world. Trade and investment increased, while barriers to migration and cultural exchange lowered (Mohamed, 2016). The European Union but also free trade agreements, such as the North American Free Trade Agreement (NAFTA), which the governments of the United States, Canada, and Mexico signed in 1992, removed barriers to the free flow of people, goods, and services, thereby facilitating greater trade, investment, and migration across borders in an unprecedented way (Profita, 2019; Puaschunder, 2018b; World Bank Group Migration and Development Brief 26, 2016).

During the last 17 years, China increased its GDP from $\$ 1.2$ trillion to $\$ 11$ trillion, a sign of historically unprecedented growth for a country of this size (Profita, 2019). A similar phenomenon occurred in India, Vietnam and other countries. Globalization also supported the growth of large multinational companies that offshored production processes and consumers to access an endless number of products at competitive prices from around the globe. Commerce soared as the cost of shifting goods in ships and planes fell, phone calls got cheaper, tariffs were cut and finance liberalized. Business went gangbusters as firms set up around the world, investors roamed and consumers shopped in supermarkets with goods from around the globe (Profita, 2019). As never before in history, traveling had become available to the general populace at affordable prices. The number of refugees reached all-time highs. If not moving oneself, free data services provided on the 'window to the world' internet, allowed everyone to consume the globe anytime anywhere.

Yet, globalization also brought about negative consequences and unforeseen shadows of the invisible hand. Until the 1990s, studies report no connection between GDP and happiness - yet from the 1990s on there is a negative correlation found between GDP and happiness (Kirchler, 2011). This trend is attributed to the internet and access to information about other places on earth's living conditions creating emotionally-hurtful comparisons in desolate places, also fueling migration trends, which has never been higher as now.

When America took a protectionist turn in its 2016 Presidential election they were, once again, first in sensing and acting on a contemporary detected, most novel worldwide trend: We currently live in the age of slowbalisation. Protectionism, trade wars, emerging economies' slowdown and the decrease in goods and services trade as well as a slump in transnational investments are all signs of the global trend of globalization have come to a halt. United Kingdom followed shortly after the US presidential with voting for Brexit. Globalization has slowed in our current times of 'slowbalisation,' a term coined in 2015 by Adjiedj Bakas, who sensed first that globalization has given way to a new era of sluggishness.

Globalization has slowed in the past decade after the 2008 global recession. Trade has fallen from 61 percent of world GDP in 2008 to 58 percent now (The Economist, January 26, 2019). If these figures exclude emerging markets (of which China is one), it has been flat at about 60 percent (The Economist, January 26, 2019). The capacity of supply chains that ship halffinished goods across borders has shrunk. Intermediate imports rose fast in the 20 years to 2008, but since then have dropped from 19 percent of world GDP to 17 percent (The Economist, January 26, 2019). The march of multinational firms has halted as the global corporate share of global profits of all listed firms has dropped from 33 percent in 2008 to 31 percent (The Economist, January 26, 2019). Long-term cross-border investment by all firms, known as Foreign Direct Investment (FDI), has tumbled from 3.5 percent of world GDP in 2007 to 1.3 percent in 2018 (The Economist, January 26, 2019). As cross-border trade and companies have stagnated relative to the economy, so too has the intensity of financial links. 
Cross-border bank loans have collapsed from 60 percent of GDP in 2006 to about 36 percent (The Economist, January 26, 2019). Excluding rickety European banks, they have been flat at 17 percent. Gross capital flows have fallen from a peak of 7 percent in early 2007 to 1.5 percent (The Economist, January 26, 2019). Since 2008 the share of economies converging from emerging economies to catch up with the rich world in terms of output per person using purchasing-power parity has fallen from 88 percent to 50 percent (The Economist, January 26, 2019). So in fact, almost all conventional measures of global trade and market integration have fallen. Tariffs have reached highest levels in the last 40 years and additional costs of trade have begun to be passed onto consumers (Profita, 2019). In the second half of 2018, the largest US companies lost about 6 billion - or 3 percent - in profits due to tariffs (Profita, 2019; The Economist, January 26, 2016). US and Chinese investments in Europe have fallen dramatically, for instance, China's investment by 73 percent in 2018 (The Economist, January $26,2019)$. The global value of foreign investment by multi-nationals decreased by 20 percent in the same year (The Economist, January 26, 2019). As the service sector appears to continue to expand, relocation for the sake of consumption has stagnated or declined as it is harder to relocate services (Buera \& Kaboski, 2012; Echevarria, 1997). Based on the last decade, The Economist (January 26, 2019) predicts a decline in exports from 28 to 23 percent of GDP over the next ten years, which would resemble a similar drop between 1929 and 1946.

Slowbalisation speaks to the fact that since the 2008 World Financial Recession, Asia's growth rates are slowing, cross-border investments, trade, bank loans and supply chains have been shrinking or stagnating relative to world GDP (The Economist, January 26, 2019). While one of the main benefits of globalization was that between 1990 and 2010 most emerging countries were able to close some of the gap with developed ones, a slowdown in globalization likely leads to a reversal in underdeveloped parts of the world catching up (The Economist, January $26,2019)$. In addition to projected major political risks and the decline in socio-economic development, with the absence of a global cooperation, it will be more difficult to tackle and solve major coordination challenges such as climate change and climate refugees, immigration and tax evasion (Baldwin, 2017; Profita, 2019). This predicament is crucial if we seem to trade off environmental degradation with international development opportunities - the two most pressing obstacles for contemporary humankind (World Bank 2015 Development Report, 2015).

Politically, where we seemed to have spent decades after two world wars to break down walls and pacify Europe in a Union, we are now back to building barriers faster than before (Profita, 2019). Since 2009, the number of new free trade agreements between countries has plummeted and restrictions on trade have proliferated on duties, anti-dumping measures and on Non-Tariff Barriers to trade (NTBs). Bloomberg reports that the DHL monitor tracking shows that global trade is continuing to lose a little steam amid an escalating tariff battle between the world's biggest economies (Profita, 2019). ${ }^{1}$ Media and news but also big data trends appear to have open gates to the world as never before while shrinking the number of local newspapers and media outlets (Hagey, Alpert \& Serkez, 2019). Corporate greed and politics of fear are partially argued as socio-political trends around slowbalisation (Profita, 2019). International remedies are called upon to ensure upholding the benefits of globalization in our commonly-shared fragile world to ensure continuous economic prosperity, societal advancement and humane dignity for all (Banerjee \& Moll, 2010).

Yet, this is not the end of the story, as some globalization features still show rising integration. Technological advances, including mobile phones and especially the internet, have contributed

${ }^{1}$ www.bloomberg.com/news/articles/2018-09-27/global-trade-growth-slowly-losing-steam-as-business-feels-pinch 
to globalization by connecting people all over the globe. Innovation spurs companies to substitute labor while technology shocks drive economic growth, especially when technologies progressively reduce the physical work component (World Bank Report, 2008). While goods are not shipped around the globe in extensive global value chains, the consumers themselves have become yet more global. The World Wide Web links billions of people and devices, providing innumerable opportunities for the exchange of goods, services, cultural products, knowledge, and ideas. The internet connectivity and volume of data crossing borders has risen by 64 times, according to McKinsey, people appear to enjoy experiences abroad and consume data. Building dreams and hope based on information shared online, migration to the rich world has risen over the past decade. International parcels and flights are growing fast, almost exponentially. As exhibited in Graph 1 derived from the Economist, ${ }^{2}$ traditional globalization features have slowed while international parcel volume, data transfer and international air travel as well as migration to the developed world continues on a globalization course. At the same time, air travel is highest ever, indicating that while goods do not travel around the globe anymore and emerging economies seem to become more versatile in producing on their own for their own needs, human do for experiences and service consumption to an extent and degree as never before in history.

Graph 1: Global stops and starts derived from the Economist

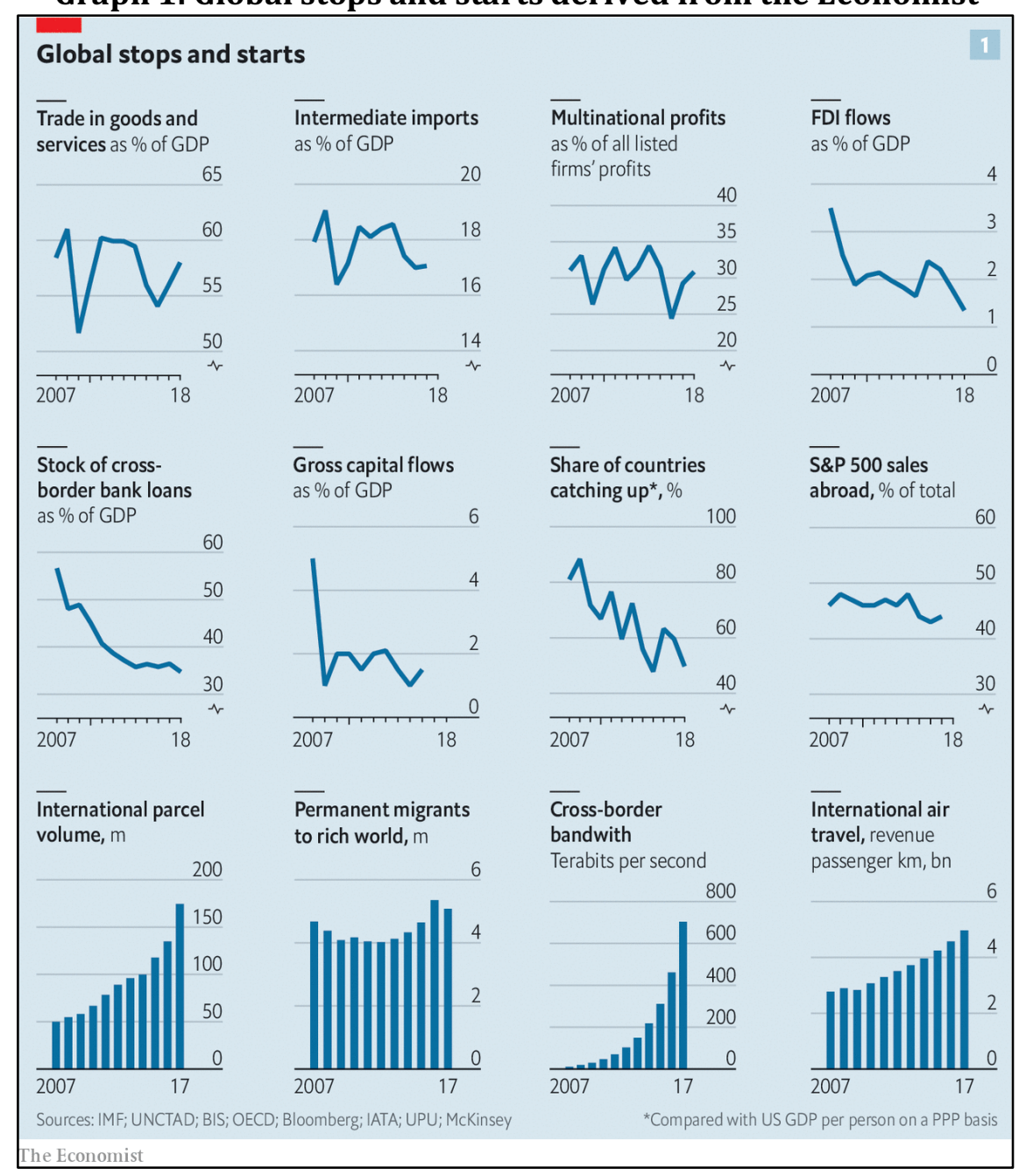

2 https://www.economist.com/briefing/2019/01/24/globalisation-has-faltered 
This trend of polarization between ongoing polarization of globalization on data and people versus slowbalisation of traditional goods and services as well as finance is argued as first sign of AI entering economic production and changing goods and service trade. Technological and political factors could indicate a market disruption that has already begun and currently echoes in globalization versus slobwbalisation occurring parallel to each other. The currently described trend of slobwbalisation could just be a forerunner of the AI revolution market disruption about to take place that will create a world very different to the one we know.

With the ringing in AI revolution, technological development is bringing production and manufacturing closer to the end user. Fourth Industrial Revolution, robots are expected to become more efficient and affordable. With that, conventional globalization practices - such as offshoring manufacturing to cheap labor cost countries - will most likely decline. Reshoring will bring back production to where goods and services are actually and finally consumed. The most obvious example is energy and a prospective attempt to decentralize renewable energy generation. Your solar panel becomes more productive if energy need not be stored but simply can be shared with your neighbor when not needed it.

Currently reshoring appears to occur, in which domestic technology-enhanced production is favored over outsourcing to desolate low-skilled, low-income territories. AI holds the potential to replicate human existence but live eternally. $24 / 7$ working robots that can live eternally are expected to become the driver of industrialized economies and replace the majority of human workforce (Lucas, 2004). 3D-printing techniques and nanotechnology that allow production to start at the molecular or even atomic level are fostering reshoring as relocating production sights from global value chain sights that were spread out during the golden years of globalization to where goods and services are consumed today. Reshoring of global production closer to where consumers are appears favorable in light of climate change and carbon emissions; yet shunning low skilled labor in developing parts of the world from production for globally operating multinationals may revert international development (Banerjee \& Duflo, 2005; Greenwood \& Jovanovic, 1990; Moll, 2014; Mookherjee \& Napel, 2007; Mookherjee \& Ray, 2003). So while companies around the globe featured an offshoring trend during the golden age of globalization, contemporary reshoring and glocalization occurs. ${ }^{3}$ Slowbalisation appears to strengthen regional trade blocs, especially in Europe and Asia (Profita, 2019; The Economist, January 26, 2019). Corporations appear to be focusing their production back to where they serve their customers and consumers have recently gained substantial interest in more local products. There is a projected impact of robotic development on international trade. Robots are expected to be more accurate and work 24/7, while being less demanding than human workers. Millions of employees in the East may lose their jobs over the next few decades, substituted by robots in the West. In addition, advances in 3D printers may soon make it possible to substitute large factories with much smaller ones, closer to the consumer, where the manufacturing process is simplified thanks to the reproduction of models (Aghion et al., 2017). New materials could be manufactured near the consumer, in order to substitute natural materials that need to be transported from distant mines and deposits (Tybout, 2000). Trade links within regional blocs may increase and blocks become more homogenous, both in Europe and Asia.

High-end production has discovered the luxury of opening consumers' eyes for the entire production and ensuring that corporate social responsibility is lived throughout the value change. Moreover, when companies bring production back into their countries for AI, unskilled workers lose out in the domestic markets while leaving behind markets that 
flourished due to outsourcing companies. ${ }^{4}$ Reshoring mean that former outsourced tasks are simply performed by AI in high skilled interconnected countries, with whom low skilled workers in the developing world now will have to compete. The transition to the new globalization has caused the workers in developed markets to lose bargaining power as they now operate in the production phases that are most vulnerable to delocalization and automation, while the Western world will face competition with AI in wage-stagnating economies (Baldwin, 2017; Barseghyan \& DiCecio, 2011; Profita, 2019). A trend which will for instance - pit a 5G automated device pit against a low skilled worker in a desolate place on earth with not even internet access, which allows learning and productivity gains (Lucas \& Moll, 2014). Slowbalisation and reshoring are thereby expected to widen the gap between the rich and the poor. AI entering our economies may lead to a trend of reshoring and thereby shunning away international low-cost production sights from global production. The global gap between AI automated hubs and non-automated places on earth will therefore likely increase in the years to come. So while reshoring offers opportunities of more sustainable production in light of climate change, when we consider the environmental impacts of shipping goods around the globe until they reach the end user; in the end, it also bears the risk of restricting global economic development.

What all of this will do to standard economic growth, we do not have data-driven answers so far. We therefore may investigate and project the impact of AI entering the workforce in standard growth theories and backtest the currently predicted slowbalisation and globalization trends' impact on economic growth.

\section{Growth theories}

The search for the determinants of economic growth has always been at the core of theoretical and empirical developments in the field of economics. Classical economists, such as Adam Smith, David Ricardo, Thomas Malthus and later Frank Ramsey and Joseph Schumpeter provided explanations for economic growth.

Traditional neoclassical growth theory assumes the presence of exogenous technological shocks as driver of economic growth. In classical, orthodox economics, economic growth is assumed to be exogenously driven based on population, technological improvement and access to natural resources. These models assume a balanced steady state solution and a balanced rate of growth to be constant and equal to the exogenous labor force growth. The Solow-Swan growth model treats capital and labor as main growth input variables that are freely substitutable, as Equation 2.1 describes:

$$
Y=f(K, L),
$$

whereby $Y$ stands for economic growth, $Y$ for capital and $L$ for labor. The free substitutability implies that if the price of labor is relatively high compared to capital, then capital can be freely substituted in place of labor until equality is reached once again (Hsieh \& Klenow, 2005, 2010). At the steady-state, an increase in capital no longer creates economic growth due to diminishing returns to capital. The only growth opportunity remaining is to invent new technologies and means of production. So, in the long run, the growth of an economy depends on technological progress, which is exogenous within the Solow-Swan framework. The main driving force behind long-run economic growth is thereby always exogenous. 
Mankiw, Romer and Weil (1992) augmented the Solow model with exogenous technology shocks. The traditional measure of economy-wide technological change, introduced by Solow (1956), is aggregate total factor productivity. This aggregate total factor productivity is an increase in output that leaves marginal rates of transformations untouched for given inputs, thus a change in total factor productivity is a form of factor-neutral technical change. Klenow and Rodriguez-Clare (1997) proposed several modifications in Mankiw et al. (1992). Problematic appeared the weak robustness of the initial model and that there was a lack in the ability to explain differences in the growth rates (Solow, 1956). The apparent and sudden emergence of a new group of interrelated Asian Tiger (Singapore, Hong Kong, Taiwan and Korea) countries, which exhibited drastic growth from the 1970s, could not be explained by the standard neoclassical Solow model (Hsieh, 2002).

Later, therefore, theories based on endogenous growth followed, which allowed for sustained per capita growth without resorting to exogenous factors emerged (Arrow, 1962, 1969; Lucas, 1988; Romer, 1986; Uzawa, 1965). Proponent of heterodox endogenous growth theory Roy Harrod (1939) moved away from a static theory of equilibrium towards a more dynamic growth approach by including a warranted rate of growth affected by the state of technology in an economy. The idea of externalities and spillover effects was originally formalized by Arrow (1962), who argued that externalities arising from learning-by-doing and knowledge spillover positively affect labor productivity on the aggregate level of the economy. This idea was picked up by Lucas and Romer in the late 1980ies as the endogenization of knowledge and technology could explain the growth that occurred in Asian countries around the 1980s (Hall \& Jones, 1999).

The so-called natural rate of growth was derived as a function of labor productivity and population. The natural rate of economic growth was described by Roy Harrod first as increase in any of these factors of production to reflect on labor and capital positively to drive growth yet with a marginally declining utility (Bjork, 1999; Harrod, 1939). Endogenous growth models are built on microeconomic foundations, where households maximize utility subject to budget constraints, while firms maximize profits (Jones, 2004). Endogenous growth theories include human capital development, knowledge spillovers as well as research and development (Aghion \& Howitt, 1992; Grossman \& Helpman, 1991a, b; Romer, 1990). Lucas and Romer included spillover effects based on Arrow (1962) and Uzawa (1965), who observed that learning-by-doing and knowledge spillover positively affected labor productivity on the aggregate level of the economy and leading to structural change (Matsuyama, 2008; Ngai \& Pissarides, 2007; Swiecki, 2017; van Neuss, 2019). Romer (1986) started with persistent growth explained by the impact of externalities on economic development (Krueger, 1997). Lucas (1988), who referred to Uzawa (1965), emphasized human capital creation as a source of growth. Uzawa (1965) and Lucas (1988) built a human capital model with education, in which the total output depends on both physical and human capital. Romer (1990) considered the creation of new knowledge as a source of growth based on Uzawa (1965), who emphasized human capital creation as a source of growth. The Lucas-Romer models are dynamic competitive general equilibrium models that are underpinned by explicit specifications of preferences and technology. For the sake of simplicity, all industries are assumed alike. As a result, each industry will employ similar amounts of capital and labor. The aggregate production function is given by

$$
Y=A K^{\alpha} L^{1-\alpha}
$$

(Equation 2.2)

whereby $A$ stands for the level of technology, which is a positive constant and $K$ represents volume of capital. $K$ embodies both physical and human capital. Lucas and Romer include 
knowledge (human capital) in their respective models to embody technological change (Kortum, 1997). The growth in human capital is what spurs technological change within the model (Jones, 2016). Romer suggests that investment in research and development, along with the given state of technology, will spur innovation that leads to growth (Kremer, 1993). Lucas (2009) emphasizes that human capital can grow from schooling as well as learning-by-doing.

Romer (1990), Grossmann and Helpman (1991) considered the creation of new knowledge as a source of growth. Aghion and Howitt $(1992,1998)$ added the Schumpeterian process of creative destruction based on research and development models (Romer, 1990). Externalities from public infrastructure were integrated by Barro $(1990,1991)$ and Futagami, Morita \& Shibata (1993). The distribution of human capital and economic growth as well as inequality in the physical to human capital accumulation were outlined by Galor and Tsiddon (1997) and Galor and Moav (2004). Kaldor (1961) emphasized that there are wide differences in the rate of growth of productivity across countries. Lucas and Moll (2014) augment growth theories with knowledge growth and productivity-increasing ideas through social interaction as well as time allocation preferences for work. Lagakos, Moll, Porzi, Qian \& Schoellman (2016) add information about lifecycle wage growth across countries. ${ }^{5}$

The question of whether the natural growth rate is exogenous, or endogenous to demand lies at the heart of the debate between neoclassical economists and heterodox post-Keynesian economists (Hausmann, Pritchett \& Rodrik, 2005). While endogenous growth theories appear more common to describe contemporary growth, endogenous growth models lack clear defining characteristics of the process, in which knowledge transforms into technological change (Manuelli \& Seshadri, 2014). Both growth model theories are built on problematic assumptions of microfoundations, such as that all firms and individuals are identical and that there is a single-sector economy with one labor market. There is an ignorance of historical and social contexts and an absence of a systemic analysis of conditions of accumulations or the socio-economic correlates of growth processes, which Post-Keynesian economists address. The use of an aggregate production function was not justifiable theoretically after the attacks by Sraffa, Robinson, Pasinetti and Garegnani during the Cambridge Capital Controversy.

\section{Cambridge Capital Controversy}

The Cambridge Capital Controversy was a debate between Cambridge in the United Kingdom and Cambridge in the United States, which started in the 1950s and lasted into the 1960s (Piketty, 2014). At the core of the debate was the nature and role of capital goods and a critique of the neoclassical vision of the aggregate production and distribution functions (Tcherneva, 2011). Joan Robinson, Nicholas Kaldor, Luigi Pasinetti, Piero Sraffa and Richard Kahn at the University of Cambridge in the United Kingdom argued for a heterodox economics opening of the production function and attention to different kinds of capital contrary to the neoclassical version of economics addressed by Paul Samuelson, Robert Solow and Franco Modigliani at the Massuchussetts Institute of Technology (MIT) in Cambridge, Massachusetts in the United States.

Piero Sraffa and Joan Robins initially set off the Cambridge Capital Controversy by pointing out in the literature that there was an inherent measurement problem in terms of capital. Capitalist income (total profit or property income) is defined as the rate of profit multiplied by the amount of capital, but the measurement of the 'amount of capital' involves adding up incomparable physical objects (Caselli \& Feyrer, 2007). Robinson argued, that capital cannot 
be added up independently of the prices of those goods. Sraffa pointed out that this financial measure of the amount of capital is determined partly by the rate of profit. A falling profit rate has a direct effect on the amount of capital; it does not simply cause greater employment of it. In addition, the Cambridge camp in the United Kingdom pointed at the neoclassical assumption of the mobility of capital. Parts of capital were assumed to be putty - flexible, movable and completely fungible. Other parts of capital were described to be clay - more bound, such as capital sunk in production sights or factories or production means or large machinery and industry. As a result of the Cambridge Capital Controversy, Paul Samuelson rejected his previously held view that heterogeneous capital could be treated as a single capital good but rather pursued multi-sectoral models (Dray \& Thirlwall, 2011).

Several economists have repeatedly argued that the capital-theoretical problems reappear in such models in a different form (Garegnani, 2008; Petri, 2009; Schefold, 2005). The controversy shed light at the problem to assume capital as a homogenous concept and opened up a multi-faceted view of capital in growth theories. However, the problems of heterogeneous capital goods have yet been ignored in the rational expectations revolution and in virtually all econometric work persist (Burmeister, 2000). To this day, we only had an opening of capital for putty and clay aspects, yet no discussion of homogenous labor components. The entrance of AI appears to make this discussion necessary.

\section{Growth in the artificial age}

Globalization led to an intricate set of interactive relationships between individuals, organizations and states (Centeno, Creager, Elga, Felton, Katz, Massey \& Shapiro, 2013). Unprecedented global interaction possibilities have made communication more complex than ever before in history as the whole has different properties than the sum of its increasing diversified parts (Centeno, \& Tham, 2012). Electronic outsourcing in the age of artificial intelligence is likely to increase and with this trend a possible societal divide in the $21^{\text {st }}$ century (Puaschunder, 2017). The AI revolution appears to be different from conventional technology shocks as the electronic information share and big data generation opens novel and yet unregulated opportunities to reap surplus value from social media consumers (Puaschunder, 2017). For one, social media space can be sold to marketers who can constantly penetrate the consumer-worker in a subliminal way with advertisements. But also nudging occurs as the big data compiled about the social media consumer-worker can be resold to marketers and technocrats to draw inferences about consumer choices, contemporary market trends or individual personality cues used for governance control, such as, for instance, border protection and tax compliance purposes (Puaschunder, 2017). Addressing these novel economic growth components in the nudgital society allows to better govern value creation in the digital age, leading to the potentially unequal accumulation and concentration of power following the greater goal to improve capitalism and democracy in the digital artificial age (Puaschunder, 2019a). In the light of growing tendencies of globalization, the demand for an in-depth understanding of how information will be shared around the globe and artificial intelligence hubs may evolve in economically more developed parts of the world has gained unprecedented momentum (Banerjee \& Newman, 1993; Kremer, Rao \& Schilbach, 2019). In addition, robotics and AI self-learning algorithms appear to resemble more human features than conventional technologies. The legal status also differs with AI being assumed to be quasi-human. First robots have gained citizenship and the legal codification of AI in common law countries bestows robots quasi-human legal status and applies the civil code in the writing of legal codification to guide on the AI introduction in markets and our contemporary society. ${ }^{6}$ With these two trends, unprecedented value opportunities from information sharing and AI

${ }^{6}$ https://techcrunch.com/2017/10/26/saudi-arabia-robot-citizen-sophia/ 
being considered quasi-human, economic growth in the artificial age may be different than neoclassical growth theory would suggest. If considering that AI takes over traditional labor and leads to a reduction of conventional production, conventional growth in the artificial age may decline. Reaping value from unconventional new AI productivity may not be captured in standard neoclassical growth components of conventional capital and labor - as Al's relation to capital and labor is unclarified. AI on the one hand seems to resemble or being treated as quasi-human but is very different from labor as for the eternal living capacities and computation power as well as interchangeability. The artificial intelligence revolution will expand our concept of time as artificial intelligence has eternal life and 24/7 productivity capacities will change tact and lifespan depreciation rates. Algorithms improving behavioral decision making biases is also not covered in capital and labor output (Beerbaum \& Puaschunder, 2018). Productivity of the sharing economy or reaping value from big data may not be displayed in standard growth components and AI is neither capital nor labor. Sharing information over a mobile app is also neither capital nor labor. Potential effects of AI on economic growth are a replacement of labor with capital as Aghion, Jones and Jones argue in 2017 based on evidence from the field. ${ }^{7}$ Yet to this day, there is no clear empirical investigation of AI's impact on ordinary production of goods and services with potential effects on growth rates and income shares (Aghion et al., 2017). While AI may help solve complex problems and save on computation time, the data computation storage may not be integrated or reflected by standard growth theories, for sure not in exogenous but also not so much in endogenous growth theory versions. Endogenous growth theory may address learning opportunities but may not accurately cope with the novel data storage and computational advantages of AI, which may increase the scope of new production lines while driving trends of reshoring and bringing back production closer to where the design and planning occurs. Reshoring may impact finance and human capital flows (Buera \& Shin, 2011; Rajan \& Zingales, 1998; Townsend \& Ueda, 2006). Human substitution through AI - such as inventing new ideas and new creative technologies - may not be captured properly in contemporary growth theories as well (Lucas \& Moll, 2014). AI may become rapidly self-improving and should be seen as a producing singularity that features unbounded machine learning intelligence and economic growth eternally (Aghion et al., 2017). Aghion et al. (2017) put forward a first integration of AI as a separate component within growth theory, so neither capital nor labor. All these features of AI encroaching markets demands for revising growth theories in light of a potential currently ongoing AI market disruption in order to draw inferences on how to revise growth theory in the artificial age.

\section{Slowbalisation}

\section{RESEARCH QUESTION AND HYPOTHESES}

In order to clarify if the currently detected slowbalisation trend is the first sign of a market disruption related to AI entering markets, the empirical investigation features Study 1 to (1) show that the currently detected polarization of globalization and slowbalisation trends is AImarket introduction driven. Study 1 validates the slowbalisation trend with particular focus on proving evidence for still ongoing globalization being connected to AI-led growth.

\section{GDP and AI-entrance}

As for the introduction of AI into contemporary economic markets, the empirical part will then (2) estimate country-differences in economic output and AI infiltration of the market in crosssectional between-country studies. Study 2 aims to clarify if AI is positively associated with economic output. Study 2 therefore captures GDP in the artificial age in a cross-sectional 
comparison between countries and offers a cross-validation check operationalized by two different AI-market entrance proxies, the Global Connectivity Index ${ }^{8}$ and The State of the Mobile Internet Connectivity 2018 Index. ${ }^{9}$

\section{GDP growth and AI-entrance}

In order to shed light on the relation of GDP growth and AI, Study 3 will (3) estimate economic growth and AI over time in cross-validated time series as well as a panel regression. Study 3 outlines the relation of AI entering markets and economic growth in a time series of economic growth for the years 1961 until 2017. The same cross-validation check of measuring the AI entrance in markets by two different proxies is given in Study 3. In order to further validate the findings and distinguish the relation of AI and growth over time from the general relation of industrialization and technological advancement leading to lower growth rates; a crosssectional regression is calculated for explaining GDP growth by AI-entrance and GDP per capita. To further validate if GDP growth is systematically related to AI-entrance, a fixed effect panel regression is calculated for explaining the relation of GDP growth to AI-entrance and GDP per capita.

\section{Study 1: Slowbalisation trend validation}

In order to consolidate the observation that there is a slowbalisation trend in conventional globalization parameters while globalization continues in the AI domain, a correlation study will be staged. As a proxy for AI entering economic markets, internet connectivity, as measured by the Global Connectivity Index ${ }^{10}$ will be related to GDP pillars of agriculture, industry and service sectors as derived from the World Bank dataset on GDP of the year 2017 and a cross-validation check be performed with the State of the Mobile Internet Connectivity 2018 Index. ${ }^{11}$ This measure should aid in understanding what GDP sectors AI is attributed to. Futher, the different components of the slowbalisation trend will be related to one another in a correlation study in order to see whether slowbalisation is a sign of AI entering markets and growth theory not being able to truly capture AI productivity. A trend of globalization still continuing in AI-featuring industries and countries will be highlighted by relating AIintegration with globalization hallmarks of capital and labor movements.

\section{Study 2: GDP in the artificial age}

Conventional growth theory components may not capture AI led growth. A macroeconomic study will investigate the relation of internet connectivity as a proxy for AI integration into the economy and GDP. In order to operationalize and consolidate the underlying premise that a currently ongoing AI introduction into markets may not be captured appropriately by standard economic growth theories, economic growth measured by GDP ${ }^{12}$ will be retrieved online form the World Bank database for the year 2017 and related to internet connectivity based on the Global Connectivity Index ${ }^{13}$ as an indicator of AI-market potential.

As a cross-validation check, internet connectivity for the year 2018 will be retrieved based on The State of the Mobile Internet Connectivity 2018 Index $^{14}$ in order to investigate another

\footnotetext{
${ }^{8}$ http://www.huawei.com/minisite/gci/en/country-rankings.html

${ }^{9} \mathrm{http}: / /$ www.huawei.com/minisite/gci/en/country-rankings.html

10 http://www.huawei.com/minisite/gci/en/country-rankings.html

11 https://www.gsma.com/mobilefordevelopment/resources/state-of-mobile-internet-connectivity-2018/

12 https://data.worldbank.org/indicator/ny.gdp.mktp.kd.zg

13 http://www.huawei.com/minisite/gci/en/country-rankings.html

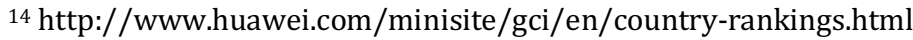


measure of internet connectivity in relation to economic output as measured in GDP output derived from the World Bank dataset on GDP.15

\section{Study 3: Time comparison of economic growth prior and after the artificial age}

In order to operationalize and consolidate the underlying premise that an AI market entrance may not be fully captured by economic growth theories, economic growth measured by GDP16 will be retrieved online form the World Bank database for the years 1961 until 2017 and internet connectivity based on the Global Connectivity Index ${ }^{17}$ homepage as an indicator of market relevance and innovation potential. Time windows of economic output and AIpresence will be compared for the periods of 2000-2017, to mark the beginning of AI entering markets, and 2008-2017 to control for post-economic crises worldwide markets. Both time windows will be compared with the rest of the data, which spans from 1961 until 1999 for a worldwide dataset.

As a cross-validation check, internet connectivity for the year 2018 will be retrieved based on The State of the Mobile Internet Connectivity Index ${ }^{18}$ over time in order to investigate another measure of internet connectivity and technology in relation to economic growth. Time windows of economic output and AI-presence will be compared for the periods of 2000-2017, to mark the beginning of AI entering markets, and 2008-2017 to control for post-economic crises worldwide markets with the rest of the data, which spans from 1961 until 1999 for a worldwide dataset. Comparing time windows of pre-AI introduction and post-AI entrance in markets allows for testing a unique relation of AI and economic growth around the world and over time.

Three regression studies will capture the relation of the entrance of AI to economic growth: Regression 1 measures the relation of GDP growth with AI-entrance by the proxies of Global Connectivity Index ${ }^{19}$ and The State of the Mobile Internet Connectivity 2018 Index. ${ }^{20}$ Regression 2 relates GDP growth with AI-entrance by the proxies of Global Connectivity Index ${ }^{21}$ and The State of the Mobile Internet Connectivity 2018 Index $^{22}$ and tests for an additional relation with GDP per capita in a cross-sectional comparison for countries of the world in 2017. Regression 3 relates GDP growth with AI-entrance and cross-validates the previous findings by using the World Bank data on Individuals Using the Internet ${ }^{23}$ in percent as a proxy AI-entrance and tests for an additional relation with GDP per capita in a fixed-effect panel regression over time employing different time windows capturing pre- and post-AI market entrance.

\section{Study 1: Slowbalisation trend validation}

\section{RESULTS}

As for testing for a concurrent slowbalisation trend in relation to GDP components, the State of the Mobile Internet Connectivity 2018 Index ${ }^{24}$ served as a proxy for AI-entrance in markets and was found to be highly significantly positively correlated with the service sector percentage of the entire GDP composition ( $\mathrm{r}_{\text {Pearson }}=.605, \mathrm{n}=161, \mathrm{p}<.000$ ) and highly significantly negatively

\footnotetext{
15 https://data.worldbank.org/indicator/ny.gdp.mktp.kd.zg

16 https://data.worldbank.org/indicator/ny.gdp.mktp.kd.zg

$17 \mathrm{http}: / /$ www.huawei.com/minisite/gci/en/country-rankings.html

18 http://www.huawei.com/minisite/gci/en/country-rankings.html

19 http://www.huawei.com/minisite/gci/en/country-rankings.html

20 http://www.huawei.com/minisite/gci/en/country-rankings.html

21 http://www.huawei.com/minisite/gci/en/country-rankings.html

22 http://www.huawei.com/minisite/gci/en/country-rankings.html

23 https://data.worldbank.org/indicator/it.net.user.zs

24 https://www.gsma.com/mobilefordevelopment/resources/state-of-mobile-internet-connectivity-2018/
} 
correlated with the agriculture GDP sector percentage of the entire GDP composition ( $\mathrm{r}_{\text {Pearson }}=-$ $.763, \mathrm{n}=161, \mathrm{p}<.000)$. The State of the Mobile Internet Connectivity 2018 Index ${ }^{25}$ was found to be highly significantly positively correlated with the total inflow of migrants ( $\mathrm{r}_{\text {Pearson }}=.263$, $\mathrm{n}=161, \mathrm{p}<.001$ ) and Foreign Direct Investment (FDI) inflow ( $\mathrm{r}_{\text {Pearson }}=.298, \mathrm{n}=159, \mathrm{p}<.000$ ). As a cross-validation check, the State of the Mobile Internet Connectivity 2018 Index ${ }^{26}$ is highly significantly positively correlated with Internet connectivity as measured by the Global Connectivity Index ${ }^{27}$ ( $\mathrm{r}_{\text {Pearson }}=.894, \mathrm{n}=79, \mathrm{p}<.000$ ), which will serve as a proxy for crossvalidating findings in Study 2 and 3.

\section{Study 2: GDP in the artificial age}

\section{Cross-sectional comparison of GDP and AI-entrance}

Regarding the relation of GDP and AI-entrance in economic markets, GDP data was derived for the year 2017 from the World Bank database on world economic output. ${ }^{28}$ AI-penetration of markets was measured by the proxy of the Global Connectivity Index ${ }^{29}$ of 79 countries. The world country GDP and the Global Connectivity Index are highly significantly positively correlated ( $\left.\mathrm{r}_{\text {Pearson }}=.344, \mathrm{n}=77, \mathrm{p}<.000\right)$.

As a cross-validation check, AI-presence in markets was also measured by the proxy of the State of the Mobile Internet Connectivity 2018 Index ${ }^{30}$ of 162 countries. The world country GDP and the State of the Mobile Internet Connectivity 2018 Index are highly significantly positively correlated $\left(\mathrm{r}_{\text {Pearson }}=.244, \mathrm{n}=160, \mathrm{p}<.002\right)$.

\section{Study 3: GDP growth in the artificial age Cross-sectional comparison and time series of GDP growth and AI-entrance}

In order to study if the found effect is a sign of industrialization and negative GDP growth, time window studies and a regression plotting GDP per capita and internet connectivity to explain GDP growth were staged.

Internet connectivity data of 79 countries based on the Global Connectivity Index ${ }^{31}$ homepage was categorized into lowest, lower, higher, and highest internet connectivity countries.

The lowest internet connectivity had Ethiopia (23), Bangladesh (24), Bolivia (25), Pakistan (25), Tanzania (25), Uganda (25), Paraguay (26), Botswana (29), Ghana (29), Kenya (29), Namibia (29), Nigeria (29), Ecuador (31), Algeria (32), India (33), Indonesia (33), Morocco (33) and Venezuela (33).

Low internet connectivity countries were Egypt (34), Jordan (34), Lebanon (34), Vietnam (34), Philippines (35), Peru (37), Argentina (38), Colombia (39), Serbia (39), Turkey (39), Thailand (40), Ukraine (41), Uruguay (41), Kazakhstan (42), Mexico (42), Oman (42), South Africa (42), Brazil (43), Belarus (44), Bulgaria (44) and Saudi Arabia (44).

High internet connectivity featured Bahrain (45), Kuwait (45), Poland (45), Romania (45), Croatia (46), Greece (46), Russian Federation (46), Chile (48), Malaysia (48), Hungary (49),

\footnotetext{
25 https://www.gsma.com/mobilefordevelopment/resources/state-of-mobile-internet-connectivity-2018/

26 https://www.gsma.com/mobilefordevelopment/resources/state-of-mobile-internet-connectivity-2018/

27 http://www.huawei.com/minisite/gci/en/country-rankings.html

28 https://data.worldbank.org/indicator/ny.gdp.mktp.cd

29 http://www.huawei.com/minisite/gci/en/country-rankings.html

$30 \mathrm{https} / /$ www.gsma.com/mobilefordevelopment/resources/state-of-mobile-internet-connectivity-2018/

31 http://www.huawei.com/minisite/gci/en/country-rankings.html
} 
Slovak Republic (49), Czech Republic (50), Italy (50), China (51), Slovenia (51), Lithuania (52), Portugal (52), United Arab Emirates (53), Estonia (54), Spain (55) and Austria (60).

The highest internet connectivity had Belgium (61), France (61), Canada (62), Ireland (62), New Zealand (62), Germany (63), Luxembourg (63), Australia (64), South Korea (64), Japan (65), Norway (65), Netherlands (67), Denmark (68), Finland (68), United Kingdom (70), Switzerland (71), Sweden (73), Singapore (75) and the United States (78).

Graph 2 outlines the world internet connectivity by highly internet-connected countries in dark blue, high internet-connected countries in blue, low internet-connected countries in green and lowest internet-connected areas in dark green based on the Global Internet Connectivity index for 2017.

\section{Graph 2: World internet connectivity from highest (dark blue) to lowest (dark green)}

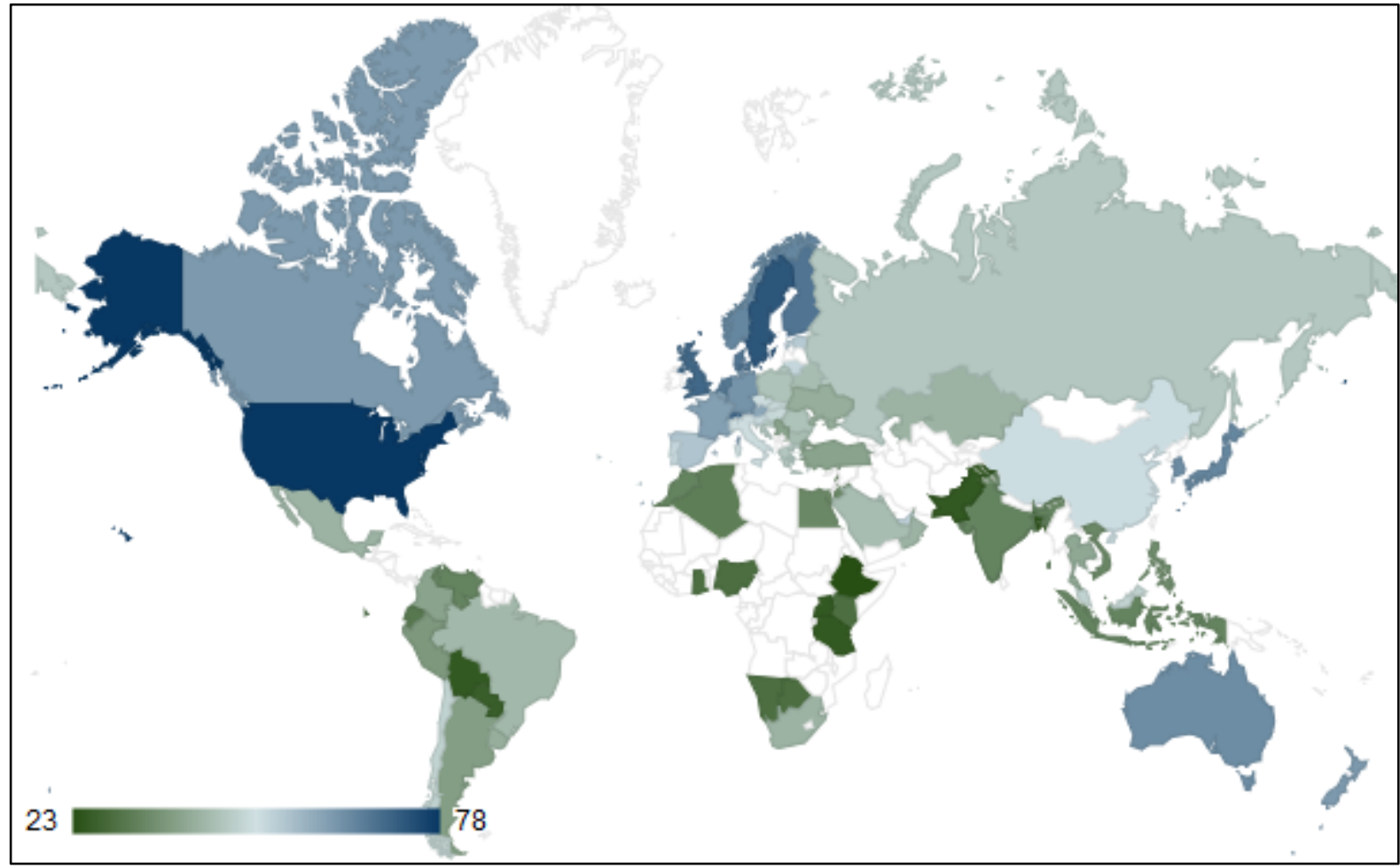

Graph 3 outlines the relation of internet connectivity and economic growth over time. From 2000 on internet-connected areas appear to show slower GDP growth rates than countries with the lowest internet connectivity. 


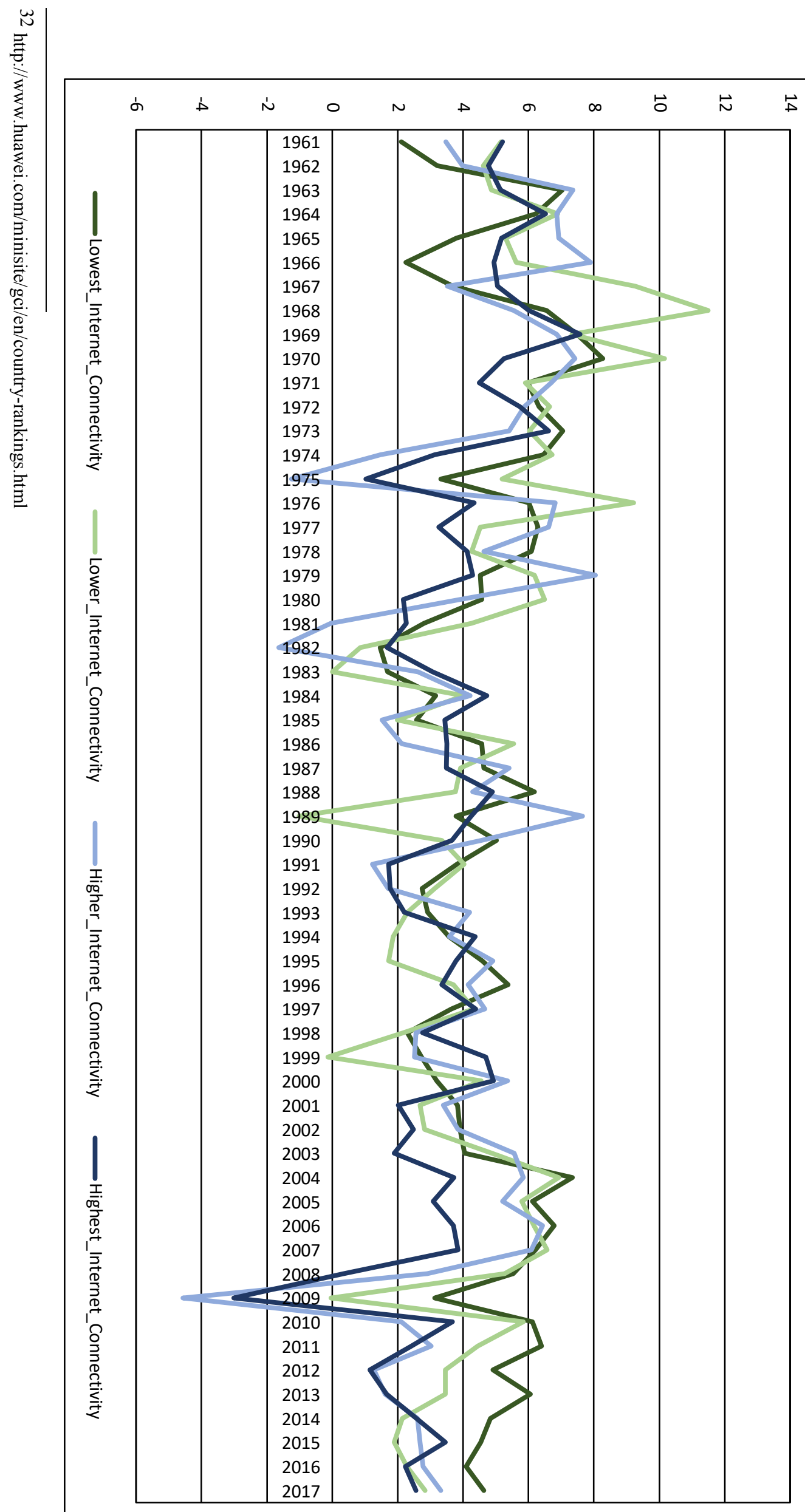

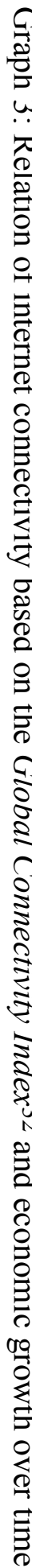


Regarding the relation of GDP and AI-entrance in economic markets over time, GDP growth data was derived for the years from 1961 until 2017 from the World Bank database on world economic output. 33 AI-penetration of markets was measured by the proxy of the Global Connectivity Index ${ }^{34}$ of 79 countries. The world country GDP growth over time was calculated for time compartments of prior to the internet revolution and after the internet revolution as well as compartments for prior and after the 2008 World Financial Recession. While internet connectivity is obviously not related to GDP growth prior to 2000, GDP growth is highly significantly negative correlated with internet connectivity for the period of the years 2008 to 2017 ( rearson $=-632, \mathrm{n}=79, \mathrm{p}<.000)$.

As a cross-validation check, internet connectivity data of 162 countries based on the State of the Mobile Internet Connectivity 2018 Index ${ }^{35}$ was categorized into lowest, lower, higher, and highest internet connectivity countries.

The lowest internet connectivity had Niger (18.56), Chad (18.73), Afghanistan (20.41), Malawi (23.66), Burundi (24.67), Burkina Faso (26.24), Democratic Republic of Congo (26.76), Mali (27.81), Guinea-Bissau (28.14), Gambia (30.95), Mozambique (31.03), Zambia (31.48), Togo (31.97), Madagascar (33.01), Liberia (33.08), Mauritania (33.48), Haiti (33.85), Sierra Leone (34.75), Uganda (36.49), Yemen (36.81), Pakistan (37.08), Benin (37.25), Senegal (37.3), Ethiopia (37.68), Timor-Leste (38.7), Nepal (39.11), Tanzania (39.4), Sudan (39.71), Rwanda (40.01), Zimbabwe (41.63), Republic of Congo (42.04), Cameroon (42.76), Tajikistan (43.77), Lesotho (43.99), Namibia (45.25), Lao (45.31), Cote d'Ivoire (45.73), Nigeria (45.91), Solomon Islands (45.91), and Papua New Guinea (46.03).

Low internet connectivity countries were Uzbekistan (46.31), Iraq (46.46), Gabon (47.68), Cambodia (47.99), Bangladesh (48.35), Angola (48.84), Kenya (50.95), Botswana (51), Kyrgyzstan (51.03), Ghana (52.73), Myanmar (53.22), Azerbaijan (53.31), Bhutan (53.57), India (53.67), Armenia (54.27), Honduras (54.91), Vanuatu (55.39), Guyana (55.59), Sri Lanka (55.63), Algeria (55.93), Nicaragua (56.08), Cabo Verde (56.17), El Salvador (56.2), Egypt (56.45), Tonga (57.77), St. Lucia (57.99), Morocco (58.04), Libya (58.79), Mongolia (58.79), Iran (59.43), Belize (59.55), Bosnia and Herzegovina (59.58), South Africa (59.89), Fiji (60.13), Georgia (60.2), Tunisia (60.38), Macedonia (60.58), Guatemala (60.75), Jordan (60.84), and Indonesia (61.12).

High internet connectivity featured Dominican Republic (61.5), Jamaica (62.23), Venezuela (62.4), Panama (62.83), Vietnam (63.03), Ukraine (63.24), Bolivia (63.57), Kazakhstan (63.58), Samoa (63.79), Costa Rica (64.27), Mauritius (64.66), Brazil (64.76), Paraguay (64.78), Colombia (64.81), Trinidad and Tobago (64.86), Moldova (65.3), Albania (65.92), Ecuador (66.23), Peru (66.61), Brunei (66.93), Philippines (67.25), Argentina (67.28), Lebanon (67.29), Mexico (67.94), Malaysia (67.97), Turkey (68.21), Belarus (68.24), Bulgaria (68.61), Oman (69.12), Barbados (70.15), Serbia (70.29), Kuwait (70.4), Saudi Arabia (70.41), Montenegro (70.45), Thailand (70.66), Bahrain (71.07), Russian Federation (71.28), Greece (72.36), Romania (72.43), Chile (72.81), and Slovak Republic (72.88).

The highest internet connectivity had Uruguay (73.34), The Bahamas (73.61), Latvia (73.68), China (73.98), Croatia (74.12), United Arab Emirates (74.27), Qatar (74.35), Hungary (74.71),

\footnotetext{
33 https://data.worldbank.org/indicator/NY.GDP.MKTP.KD.ZG

${ }^{34}$ http://www.huawei.com/minisite/gci/en/country-rankings.html

35 https://www.gsma.com/mobilefordevelopment/resources/state-of-mobile-internet-connectivity-2018/
} 
Italy (74.86), Lithuania (75.26), Cyprus (75.99), Czech Republic (76.29), Malta (76.33), Poland (76.69), Israel (77.08), Estonia (77.71), Slovenia (77.76), Spain (79.7), France (79.87), Japan (80.04), Hong Kong (80.73), Luxembourg (81.42), Belgium (81.59), Germany (81.78), United States (81.81), Austria (82.41), Ireland (83.05), South Korea (83.37), Switzerland (83.7), Netherlands (84.16), United Kingdom (84.18), Finland (84.19), Canada (84.33), Sweden (84.33), Denmark (84.45), Norway (86.43), Singapore (86.55), Iceland (86.58), New Zealand (87.85), and Australia (88.94).

Graph 4 sums up the categorization into highest internet connectivity countries in dark blue, high internet connectivity countries in blue, low internet connectivity countries in green and lowest internet connectivity in dark green based on the State of the Mobile Internet Connectivity 2018 Index. ${ }^{36}$

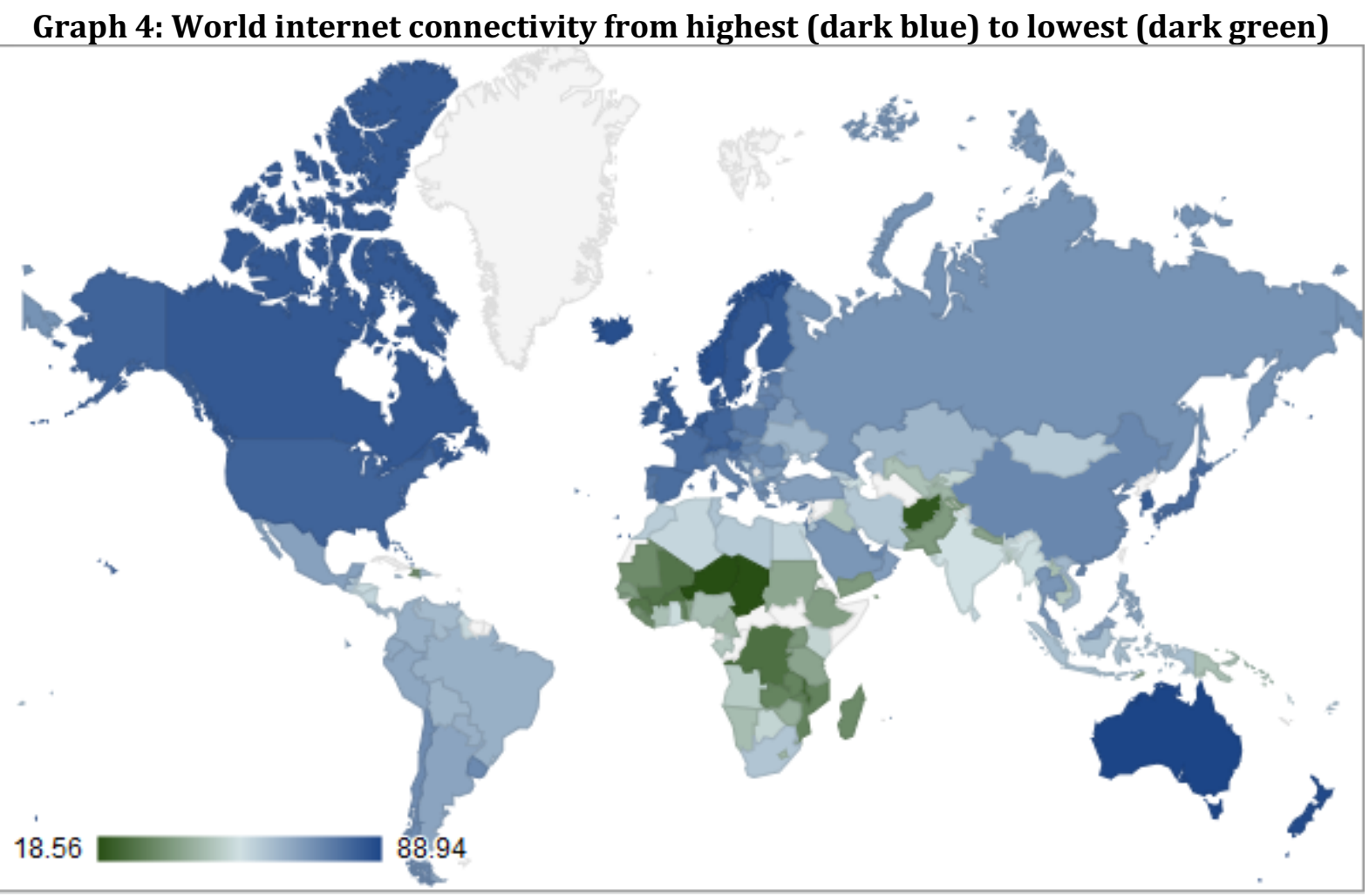

Graph 5 outlines the relation of internet connectivity based on the State of the Mobile Internet Connectivity 2018 Index ${ }^{37}$ and economic growth over time. From 2000 on internet-connected areas appear to show slower growth than countries with the lowest internet connectivity. 
Graph 5: Relation of internet connectivity based on the State of the Mobile Internet Connectivity 2018 Index ${ }^{38}$ and economic growth over time

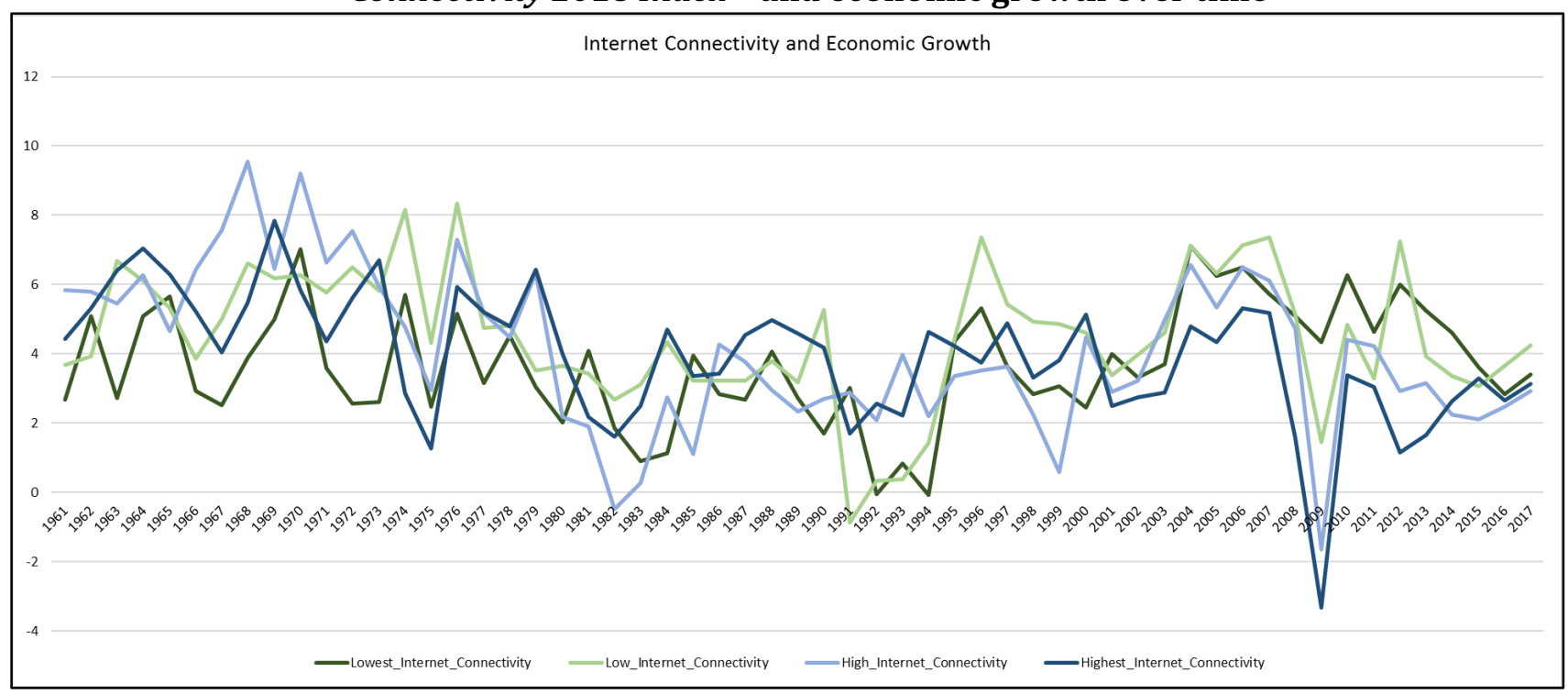

As a cross-validation regarding the relation of GDP and AI-entrance in economic markets over time, GDP growth data was derived for the years from 1961 until 2017 from the World Bank database on world economic output. ${ }^{39}$ AI-penetration of markets was measured by the proxy of the State of the Mobile Internet Connectivity 2018 Index $^{40}$ of 160 countries. The world country GDP growth over time was calculated for time compartments of prior to the internet revolution and after the internet revolution as well as compartments for prior and after the 2008 World Financial Recession. While internet connectivity is not related to GDP growth prior to 2000, GDP growth is highly significantly negatively correlated with internet connectivity for the period of the years 2000 to 2017 ( Pearson $_{\text {Pe }}=375, n=160, p<.000$ ).

A regression plotting Internet Connectivity and GDP per capita as independent variables to explain the dependent variable GDP growth outlines that the effect for AI is a significant determinant of negative GDP growth prospects for the years from 2000 until 2017.

Method: To investigate H1.1 on the relation between GDP and AI entrance in markets, a crosssectional regression was calculated to clarify in-between country differences of AI entrance affecting GDP growth.

The regression reads the equation 4.1

$$
\mathrm{y}_{\mathrm{i}}=\alpha+\beta \mathrm{GDPc}_{\mathrm{i}}+\beta A \mathrm{Ic}_{\mathrm{i}}+\varepsilon_{\mathrm{i}}
$$

whereby

$y=$ the GDP growth as outlined by the World Bank database for the years from 2000 until 2017 from the World Bank database on world economic output. ${ }^{41}$

$\mathrm{i}=$ index of country with $\mathrm{i}$...N;

$\mathrm{GDP}_{\mathrm{i}}=\mathrm{GDP}$ per capita of country $\mathrm{i}$ in 2018 as measured by the International Monetary Fund; ${ }^{42}$

\footnotetext{
38 https://www.gsma.com/mobilefordevelopment/resources/state-of-mobile-internet-connectivity-2018/

39 https://data.worldbank.org/indicator/NY.GDP.MKTP.KD.ZG

40 https://www.gsma.com/mobilefordevelopment/resources/state-of-mobile-internet-connectivity-2018/

41 https://data.worldbank.org/indicator/NY.GDP.MKTP.KD.ZG

42 https://www.imf.org/external/pubs/ft/weo/2019/01/weodata/
} 
$\mathrm{AIc}_{\mathrm{i}}=\mathrm{AI}$ entrance into economic markets as measured by the State of the Mobile Internet Connectivity 2018 Index; 43

$\varepsilon_{\mathrm{i}}=$ standard error term

The regression was targeted at investigating whether industrialization being associated with lower GDP growth rates is the driving effect. The regression therefore plotted GDP per capita and AI entrance in markets as measured by the State of the Mobile Internet Connectivity 2018 Index ${ }^{44}$ as independent variables against the dependent variable of GDP growth rates.

To describe the relation of AI entrance in markets and GDP growth operationalized by State of the Mobile Internet Connectivity 2018 Index ${ }^{45}$ of 161 countries, a regression was calculated that reveals an overall low fit with R square of .147 and adjusted R square of .136 of the model. The regression coefficient $B$ value of -.054 for $A I$ entrance in markets is significant at the 5 percent one-sided t-testing level, with a $p$-value of 0.000 , whereas GDP per capita is not significant.

Method: To investigate H2.1 on the relation between GDP and AI entrance in markets over time, a fixed-effects panel regression was calculated to clarify over-time in-between country differences of AI entrance affecting GDP growth.

The regression reads the equation 4.2

$$
\mathrm{y}_{\mathrm{it}}=\mathrm{c}_{\mathrm{i}}+\mathrm{d}_{\mathrm{t}}+\beta \mathrm{GDP}_{\mathrm{it}}+\gamma \beta \mathrm{AI}_{\mathrm{it}}+\delta \beta A \mathrm{I}_{\mathrm{it}-1}+\varepsilon_{\mathrm{i}},
$$

(Equation 4.2)

whereby

$y_{\text {it }}=$ the GDP growth as outlined by the World Bank database for the years from 2000 until 2017 from the World Bank database on world economic output. ${ }^{46}$

$\mathrm{i}=$ index of country with i...N;

$\mathrm{t}=$ time as measured per year with $\mathrm{i} . . . \mathrm{N}$;

$c_{i}=$ country intercept fixed effect;

$\mathrm{d}_{\mathrm{i}}=y$ ear intercept fixed effect;

$\mathrm{GDPC}_{\mathrm{i}}=\mathrm{GDP}$ per capita of country $\mathrm{i}$ in years $\mathrm{t}$ as measured by the World Bank; ${ }^{47}$

$\mathrm{AIC}_{\mathrm{i}}=\mathrm{AI}$ entrance into economic markets as measured by the State of the Mobile Internet Connectivity 2018 Index; 48

$\gamma \beta A I_{i t}=A I$ time period 1 ;

$\delta \beta \mathrm{AI}_{\mathrm{it}-1}=\mathrm{AI}$ time lag previous year before period 1 ;

$\varepsilon_{\mathrm{i}}=$ standard error term

The regression was targeted at investigating whether industrialization being associated with lower GDP growth rates is the driving effect over time. The regression therefore plotted GDP per capita and AI entrance in markets as measured by the State of the Mobile Internet Connectivity 2018 Index $^{49}$ as independent variables against the dependent variable of GDP growth rates over time from the years 2000 to 2017 for 214 countries. The regression reports two way clustered errors.

\footnotetext{
${ }^{43}$ https://www.gsma.com/mobilefordevelopment/resources/state-of-mobile-internet-connectivity-2018/

44 https://www.gsma.com/mobilefordevelopment/resources/state-of-mobile-internet-connectivity-2018/

45 https://www.gsma.com/mobilefordevelopment/resources/state-of-mobile-internet-connectivity-2018/

46 https://data.worldbank.org/indicator/NY.GDP.MKTP.KD.ZG

47 https://data.worldbank.org/indicator/ny.gdp.pcap.cd

48 https://www.gsma.com/mobilefordevelopment/resources/state-of-mobile-internet-connectivity-2018/

49 https://www.gsma.com/mobilefordevelopment/resources/state-of-mobile-internet-connectivity-2018/
} 
To describe the relation of AI entrance in markets and GDP growth operationalized by State of the Mobile Internet Connectivity 2018 Index ${ }^{50}$ of 161 countries, a regression was calculated that reveals an overall low fit with $\mathrm{R}$ square of .014. The regression coefficient $\mathrm{B}$ value of -.059 for AI entrance in markets is significant at the 5 percent one-sided t-testing level, with a $p$-value of 0.017 (see Model 1 in Table 1), whereas as model 2 reveals GDP per capita is not significant as visible in Table 1. Testing for an assumed time lag for internet adoption of 1 year, the regression coefficient $B$ value of -.051 for $\mathrm{AI}$ entrance in markets is significant at the 5 percent one-sided t-testing level, with a $p$-value of 0.019 (see Model 3 in Table 1), whereas as model 3 reveals GDP per capita is not significant as visible in Table 1. Testing for an assumed time lag for internet adoption of 1 year, the regression coefficient B value of -.051 for AI entrance in markets is significant at the 5 percent one-sided t-testing level, with a $p$-value of 0.019 (see Model 3 in Table 1), whereas as model 3 reveals GDP per capita is not significant as visible in Table 1. AI entrance is negatively associated with GDP growth over time from 2000 on until 2017, whereas GDP per capita is not a relevant indicator on GDP growth.

Table 1: 2000 to 2017

\begin{tabular}{llll}
\hline & Model 1 & Model 2 & Model 3 \\
\hline GDPc & & -0.000 & 0.000 \\
& & $(0.000)$ & $(0.000)$ \\
AI & $-0.059^{* * *}$ & $-0.056^{* *}$ & \\
& $(0.017)$ & $(0.018)$ & \\
lag(AI) & & & $-0.051^{* *}$ \\
& & & $(0.019)$ \\
$\begin{array}{llll}\text { Country and year } \\
\text { fixed effects }\end{array}$ & Yes & Yes & Yes \\
\hline $\mathrm{R}^{2}$ & 0.014 & 0.013 & 0.008 \\
Num. obs. & 3466 & 3450 & 3255 \\
${ }^{* * *} \mathrm{p}<0.001,{ }^{* *} \mathrm{p}<0.01,{ }^{*} \mathrm{p}<0.05$ &
\end{tabular}

\section{Overall results discussion}

In summary over all the results, slowbalisation appears to be connected to human migration and differing from the currently ongoing AI revolution. Trade and transfer in data and the knowledge economy is still globalizing, while conventional globalization trends of moving goods and finance has been slowed. A current market trend towards novel technologies, such as big data capital gain, reshoring or AI taking over former human capital labor tasks is detected, which appears to be connected to GDP components of the service sector (Foster \& Rosenzweig, 2010). In both measurements of global connectivity as a proxy for AI entering markets from around the turn of the millennium on, higher internet connectivity is associated with lower economic growth. This striking result demands for revisiting growth theories. AI hubs are speculated to have growth - e.g., such as gains from the sharing economy, cryptocurrencies and big data that conventional growth theory may not include. AI entrance is negatively associated with GDP growth, whereas GDP per capita is not a relevant indicator on GDP growth as was found in a cross-sectional regression and a fixed effects country panel regression. The panel regression plotting GDP per capita and internet connectivity from the year 2000 to explain economic growth therefore consolidates the overall finding that internet connectivity is associated with economic growth decline over time and over 161 countries of the world, whereas GDP per capita has no significant relation with GDP growth. We may 
therefore advocate for revising conventional orthodox and heterodox growth theory for integrating AI led growth.

\section{DISCUSSION}

In today's economy, robots and algorithms are taking over human decision-making tasks and entering the workforce. Most recently, big data has evolved to become a source of major assets and governments around the world are endeavoring to tax wealth creation from information transfer. This trend currently challenges conventional economic theory to capture growth based on purely capital and labor components. Algorithms, machine learning and big data gains but also the shared economy do not seem to be represented accurately in conventional growth theory components of capital and labor (Alvarez, Buera \& Lucas, 2007).

It is therefore proposed that contemporary growth theory should be revised as for integrating growth related to AI. First, it should be theoretically clarified, measured and backtested on data whether AI enhances or lowers capital and/or labor components of standard growth theories. Second, as the data suggests, growth theory should consider labor to be either flexible, as would potentially be AI components, or more inflexible, as would be traditional human labor force. Third, micro-macro and endogenous and exogenous growth theories should integrate a novel component for AI as comprised of machine learning, big data and robotics. The new growth theory proposed is:

$$
Y n(t)=(A(t) K(t))^{\alpha}(A(t) L(t))^{\beta}(A(t) I(t))^{1-\alpha-\beta} \quad \text { (Equation 6.1) }
$$

whereby $Y n(t)$ denotes total new production function, $A(t)$ refers to capital and laboraugmenting technologies or AI knowledge, $K(t)$ is capital and $L(t)$ labor. $I(t)$ represents information, which internet connectivity has made more accessible. Information share and big data storage as well as computation power are most novel features of AI. Access to information but also reaping benefits from information sharing through synergizing information and deriving inferences in relation to big data is an innovative value generation in the artificial age differing from conventional capital or labor. Having already a big data collection enhances the productivity of $I(t)$ due to network effects and information being a non-rivalrous good, with a marginal utility gain that is exponential. Network effects from information and connectivity increase per additional user. Information is non-rivalrous as the consumption of one piece of information does not decrease or deplete the opportunity for another person to consume the information. The more information one holds, the better hence the marginal utility of information rises exponentially with information gain. In all these features - network effect gains, non-rivalrous information consumption opportunities and exponential marginal utility gains of knowledge - information is completely different classical notions of capital and labor. Where capital and labor are exclusive, the knowledge economy and big data driven growth are non-exclusive (Clancy, 1998). A piece of information shared or written online does not does not take anything away or decrease utility, it actually increases people's utility non-depletable (Stiglitz, 1998; Stroebe, \& Frey, 1982). Therefore, it is proposed to measure AI as completely novel component to be considered in standard growth theory. Economically, the current AI revolution is thus believed to differ from conventional technology shocks by the knowledge economy obeying different laws of economic exchange (Lucas, 2004). Addressing the found deficiency of an integration of AI into standard growth calculus leads to the creation of an index AI_GDP per country c based on Equation 6.2, comprised of the GDP per capita and AI internet connectivity percentage of a country.

$$
A I_{-} G D P(c)=G D P_{\text {per capita }}(c) * I A(c)
$$

(Equation 6.2) 
whereby $A I_{-} G D P(c)$ denotes the AI-GDP index per country $c$ calculated by GDP per capita of a country $c$ as retrieved from a World Bank database ${ }^{51}$ multiplied by $I A(c)$, which represents country $c$ inhabitants' internet usage in percent of the population as retrieved from a World Bank database. ${ }^{52}$ Table A 1 in the appendix holds the $A I_{-} G D P(c)$ index value per country. Graph 6 tables the $A I_{-} G D P$ countries' indices ranked from the highest to the lowest.

Graph 6: AI-GDP Index for 191 countries of the world

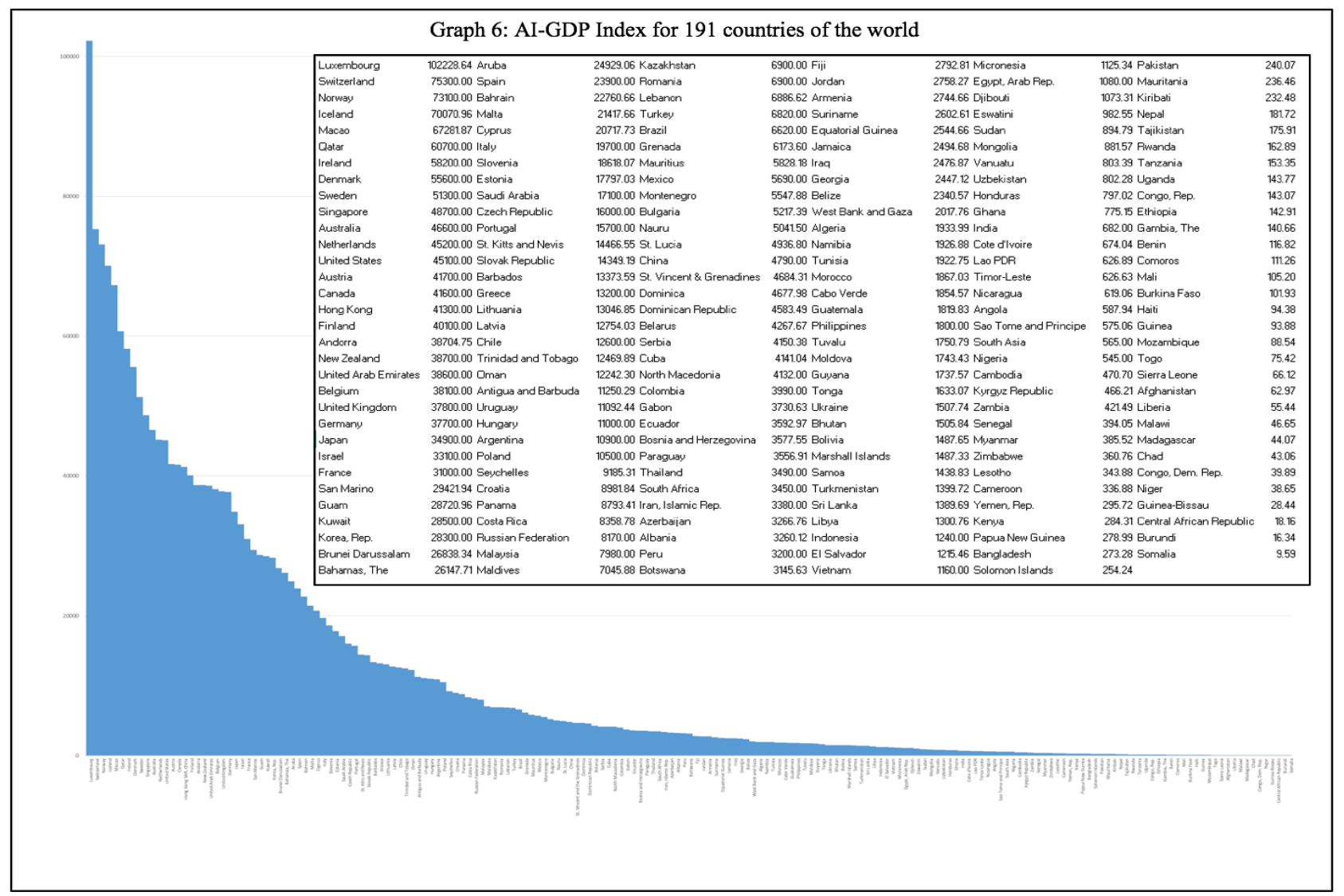

Graph 7 displays the $A I_{-} G D P$ country's index around the world. The higher the index, the darker the country is colored.

\footnotetext{
51 https://data.worldbank.org/indicator/ny.gdp.pcap.cd

52 https://data.worldbank.org/indicator/it.net.user.zs
} 
Graph 7: AI-GDP Index for 191 countries of the world

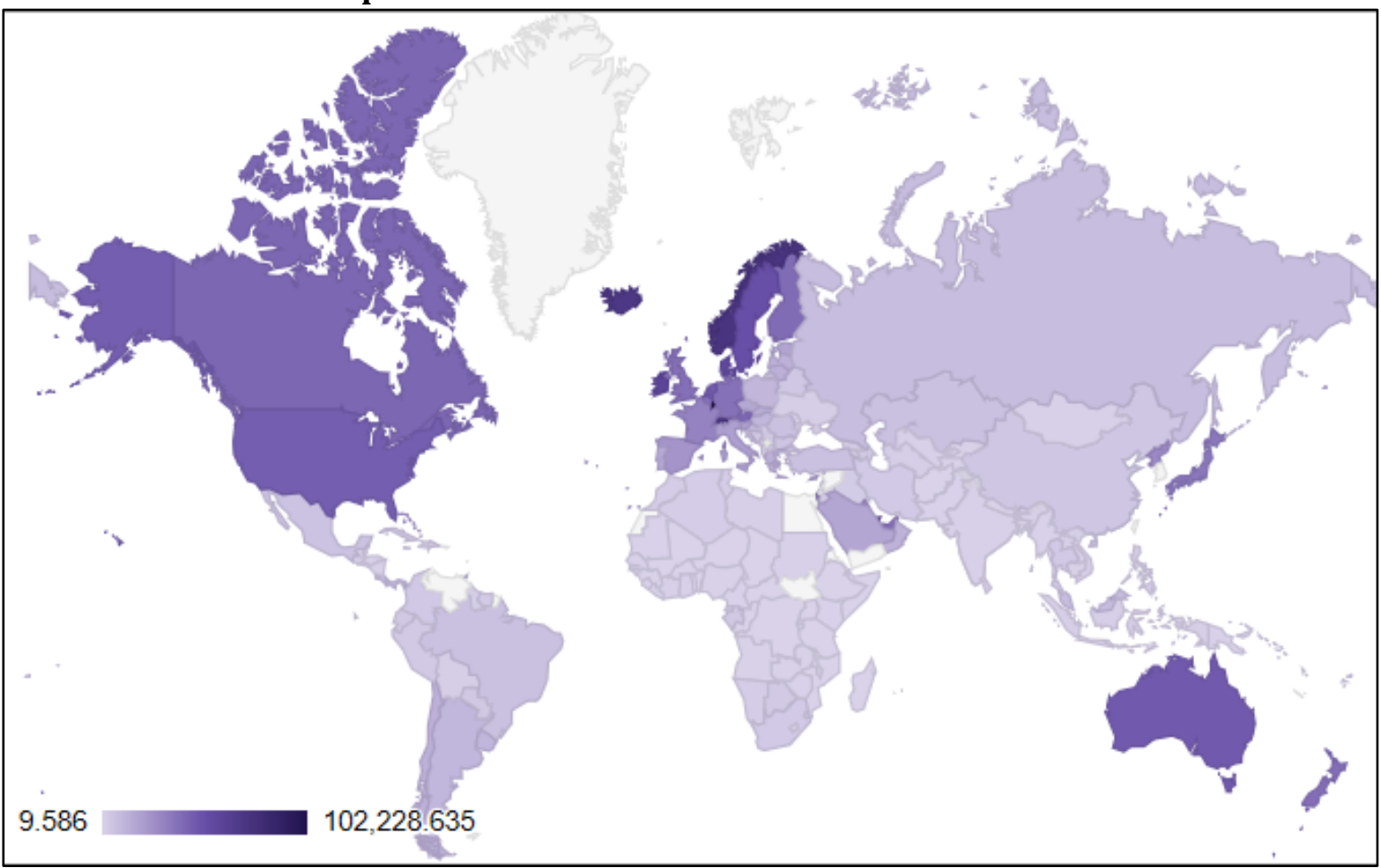

As visible in Graphs 8-13, continent specific AI-GDP indices reveal Africa being relatively low on AI-GDP - see Graph 8. Asia and the Gulf region being in the middle ranges with Qatar and United Arab Emirates and Japan and South Korea leading as outlined in Graph 9. Graph 10 reveals in Europe Luxembourg, Switzerland, Norway, Iceland, Ireland, Sweden and Finland as top AI-GDP countries. North America (Graph 11) has a higher AI-GDP index than South America (Graph 12), where Chile, Argentina and Uruguay appear to lead. In Oceania Australia has the highest AI-GDP index followed by New Zealand as visible in Graph 13.

\section{Graph 8: Africa AI-GDP index}

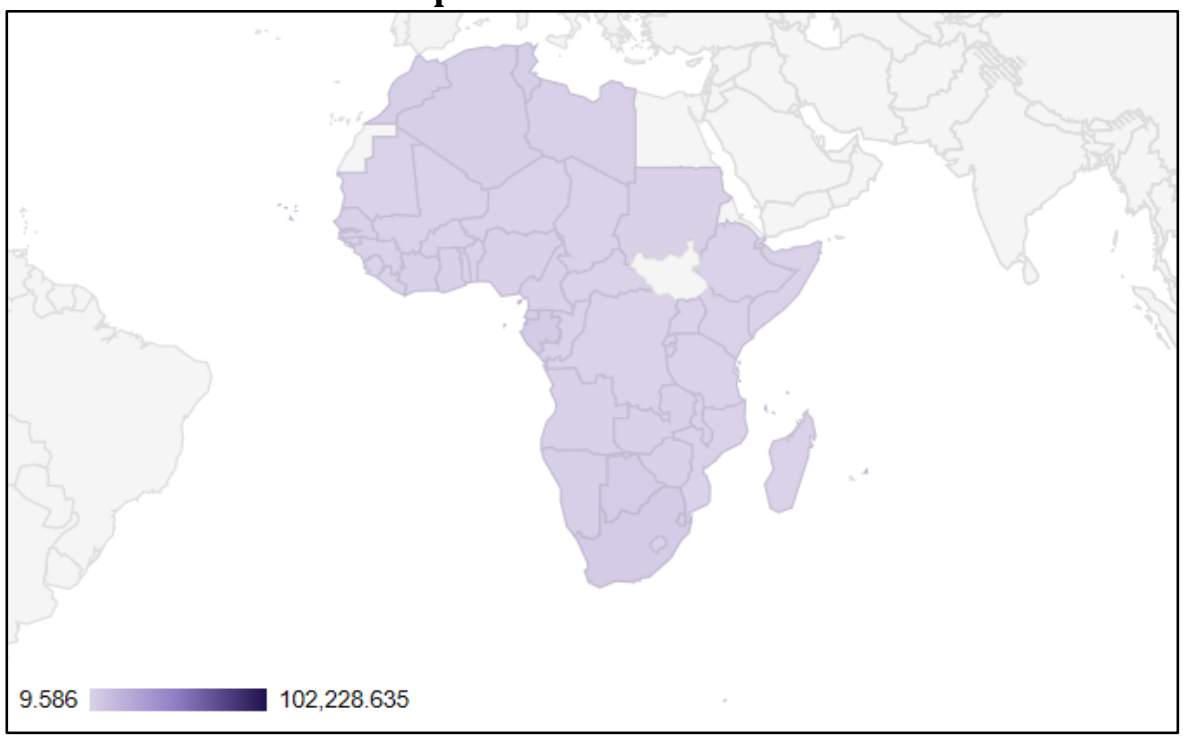



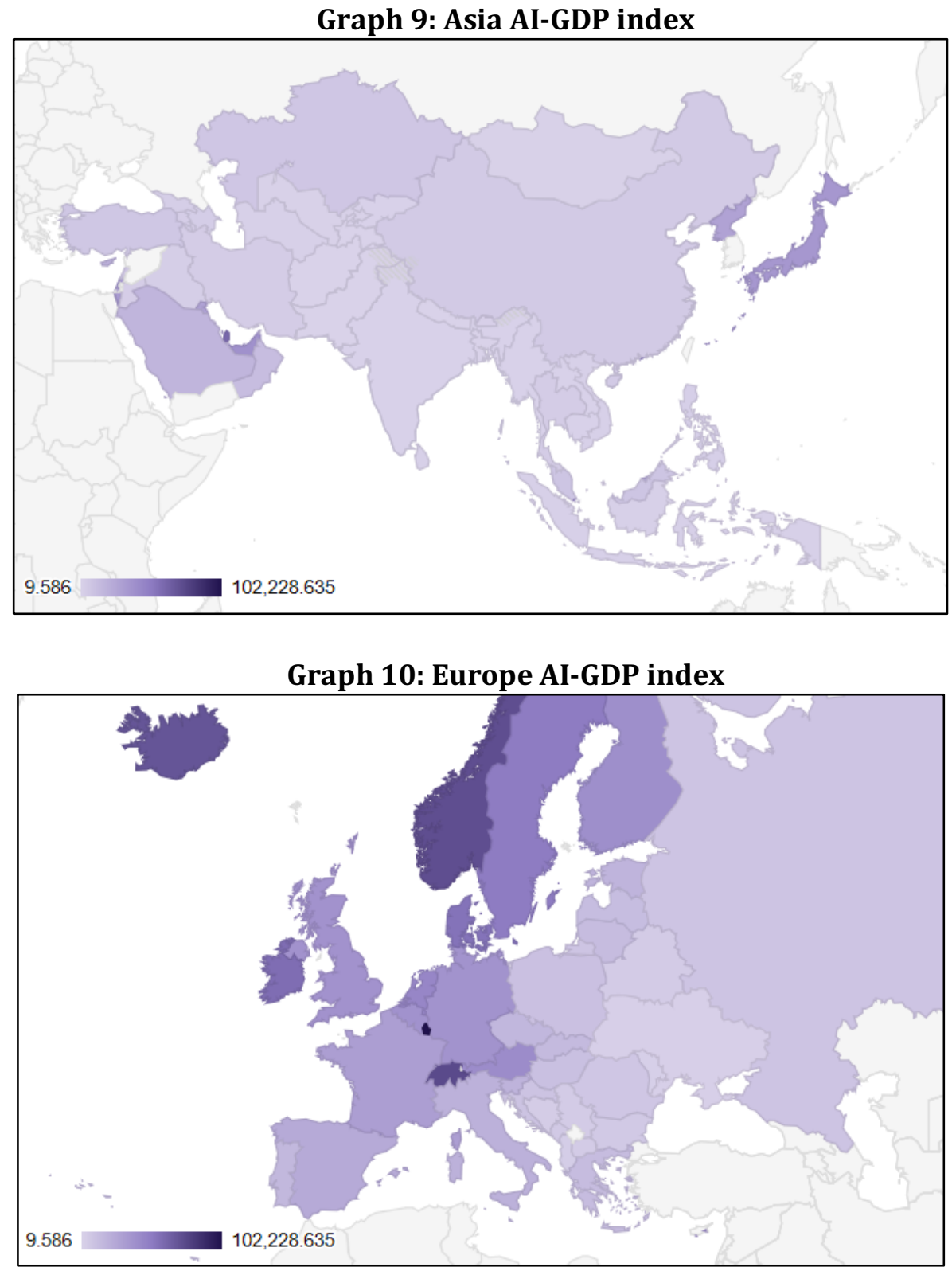

\section{Graph 11: North America AI-GDP index}

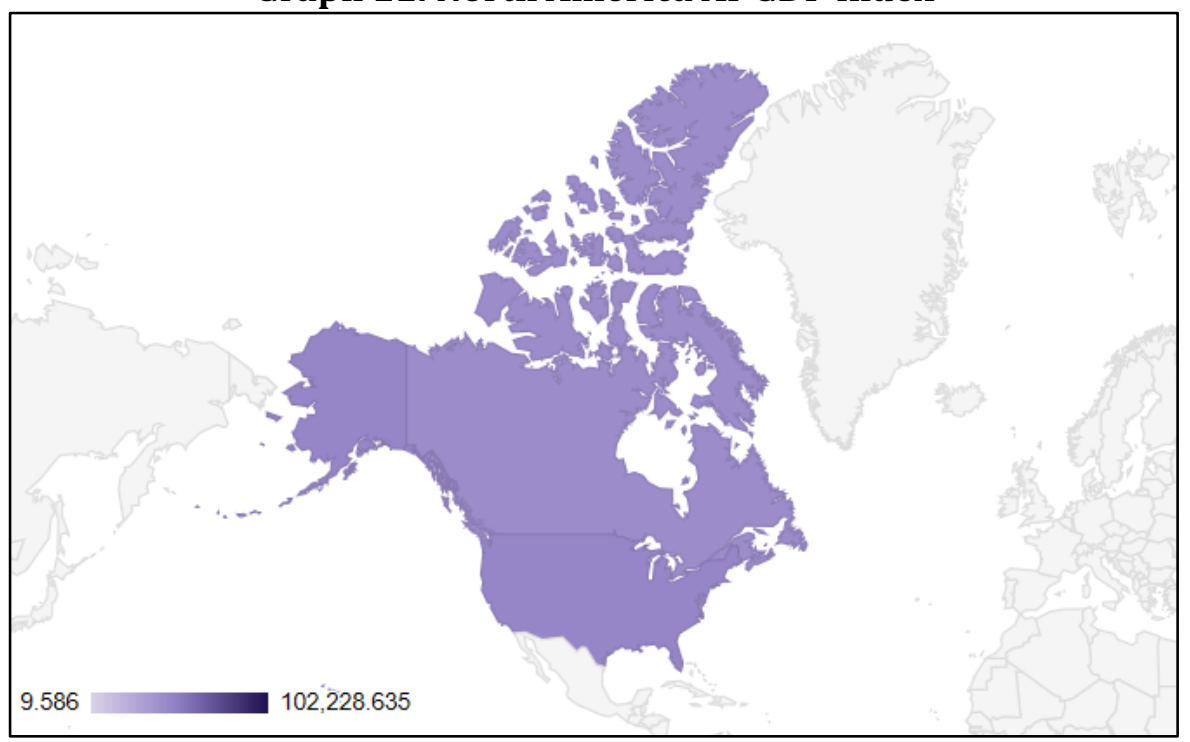



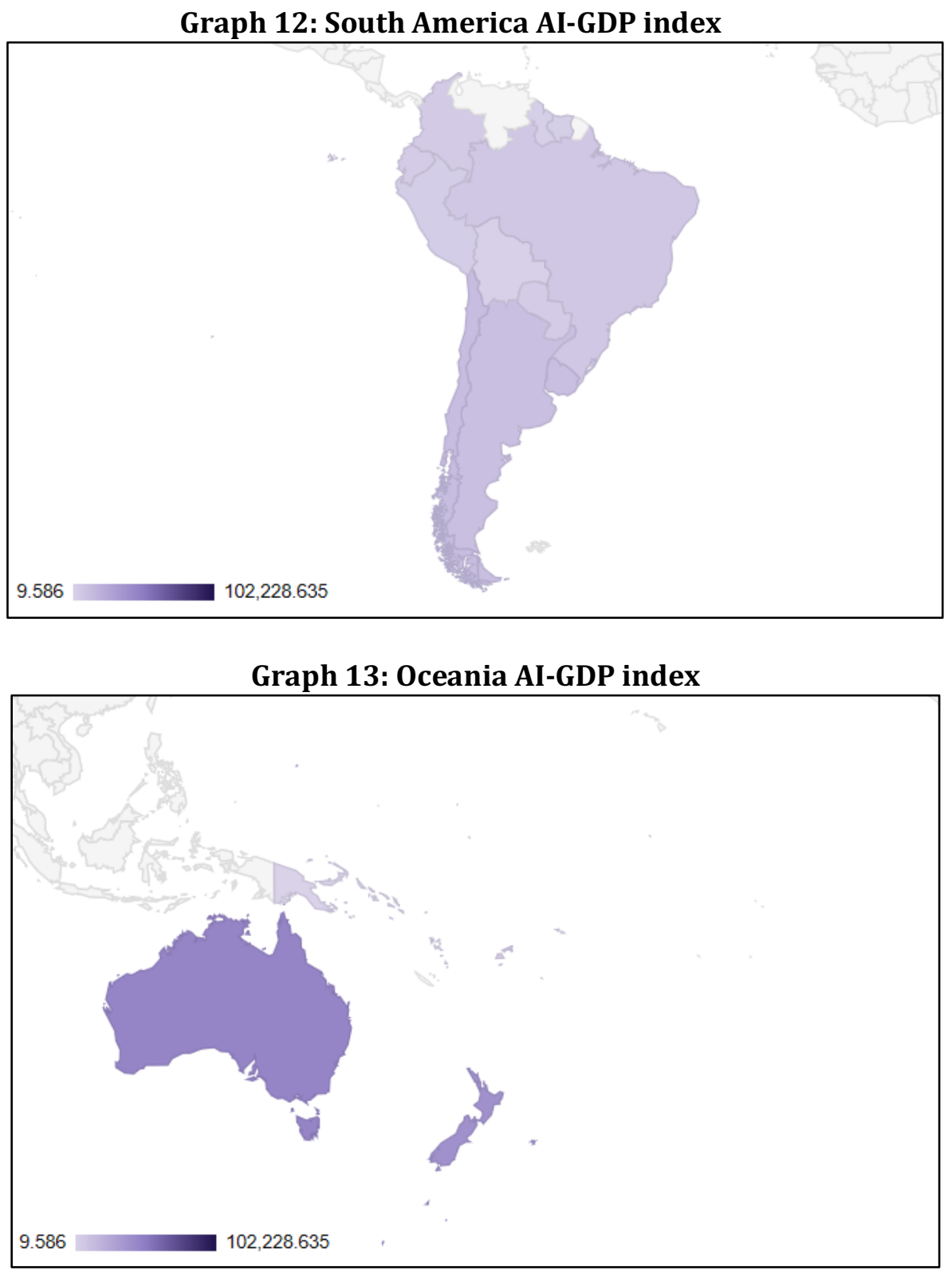

As a predicted trend, the co-existence of AI with the human species is believed to change the fundamental concepts of economic growth. Already now, we see a market disruption happening. Traditionally globalizing areas of growth seem to stagnate while AI driven industries are continuously globalizing.

When considering growth theories, we may first answer the question where AI led growth will be driven from. AI appears as exogenous technology shock that may increase labor productivity. With this going along is a transition of the economy and legal understanding of AI. What is different in regards to AI from conventional traditional technology shocks is the missing legal framework and economic clear distinction into capital or labor. The discussion therefore covers a legal and economic analysis of what AI may represent to then propose to integrate $\mathrm{AI}$ as an additional growth component in growth theories.

AI has already produced novel legal creations and will do so even more in the near future, through its developing autonomy. A new legal category for AI is currently created that may instigate a new labor component in growth equations. Robos are currently partially considered as quasi-human beings in common law territories as for forming an intellectual autonomy as singular legal entities (MacDonald, 2016). In Saudi Arabia the first female robot 
got a citizenship in 2017 and appears to have more rights than a human female in Saudi Arabia. Interestingly, Sophia was financed by North American investors, put together in Hong Kong and rolled out in Saudi Arabia, where Sophia - and by now her siblings - hold citizenship. ${ }^{53}$ Other attempts to classify AI are considering robots as quasi-slaves, whose sole purpose is to reap economic value from (Dillon \& Garland, 2005; Gamauf, 2009; Harris, 2000; Puaschunder, 2019). An additional proposal lies in considering robots as quasi-human beings, with different citizenship rights than actual humans in order to uphold pro-social norms (Puaschunder, $2019 \mathrm{a}, \mathrm{b}$ ). Behavioral economists add the question whether AI and robots should be created to resemble human beings' decision making with fast thinking and fallible choices or rather be targeted at perfect rationality and slow thinking (Kahneman \& Tversky, 1979). General conscious is strived for so that AI possesses consciousness, which it can evolve and enhance on the basis of its own critical reflection and assessment of external factors (Mauss, 1979; Themistoklis, 2018). A lower level of autonomy exists if an entity can demonstrate such consciousness at a narrow field or can self-evolve and self-adapt to external influences, thus reaching decisions of its own, without being conscious of its intelligence as such (Themistoklis, 2018). As AI emerges as new types of intellect capacities coupled with human-like emotional features, they are attributed a legal personhood in order to ensure to be comprehended correctly and to avoid unfair treatment, towards humans as well (Themistoklis, 2018). Respectful treatment of AI is meant to protect and uphold dignity of all people and AI. Upholding certain ethics in regards to AI appears favorable to breed social norms but certain privileges should only be granted to human workers (Kirchler, 2007; Lin, Abney \& Bekey, 2012; Mumford, 2001). Legal codifications have existed in history, which granted different citizenship rights to citizens, e.g., in the Athenian city state, Roman empire slavery and during Napoléon, when male and female had substantial differences in access to property rights and resources. Similar concepts could be used for classifying the difference between AI and human labor.

With citizenship and quasi-humanness being attributed to AI, the power relation between human and AI will need to be defined (Solum, 1992). Should AI be granted full citizenship rights, the problem of overpopulation occurs, since there is the possibility of infinite life of AI. With the rise of AI persons, their eternal life poses ethical challenges in light of overpopulation and evolutionary perfection, which could crowd out human fallibility if determining meritbased eternal life. In a human-led evolution, AI will have to be switched off for various reasons, such as malfunction but also merit-based efficiency calculus. If now AI is considered as quasihumane and granted citizenship rights, switching off AI becomes a legally problematic. A human-led evolution may lead to having to decide what AI developments to favor and pursue and clear guidelines when to terminate a malfunctioning or defect AI. In this feature AI will be different from labor as for having the potential to live eternally and being more malleable to be changed and switched. AI will be flexible and interchangeable in the international arena. Again, a putty labor definition of AI components of labor is recommended that captures the difference of AI to conventional labor in this regard.

When considering the enormous physical and longevity advantages AI hold over human, a natural dominance of AI over humankind is implied. In order to ensure that human lead AI and are not subordinated, a society should be established, in which robots gain quasi-human rights but may not have the same powers and rights as human beings (Vlassopoulos, 2009). In the earliest form of democracy in the ancient Athenian city state, different classes of citizenship existed. In the ancient Athenian democracy model, not every citizen had the right to vote, run 
for office and participate in political discussions (The Oxford Encyclopedia of Ancient Greece and Rome, 2010). Yet to all, the democracy was meant to protect and uphold dignity of all people. Therefore, the Athenian democracy bestowed a favorable climate in society without political equality of all citizens. The Athenian form of direct democracy does not only serve as an example of not all citizens being allowed to vote being a feasible governmental structure but also - as for its direct character - as a forerunner of electronic democracy. A future world with AI blended into society could structure the human - AI relation based on the ancient Athenian city state societal composition, in which different classes of citizenship lived together in harmony. As in the ancient Athenian democracy model, not every citizen should have the right to vote, run for office and participate in political discussions. AI could become citizen, yet not be allowed to vote, run for office and participate in political discussions.

AI entering the workforce and holding enormous physical and longevity advantages over human but no felt emotions, implies economic gains to be reaped. Standard economic growth models hold that capital and labor are essential for an economy to flourish. While capital is usually considered as fungible, exchangeable and eternal, labor is more individual, human and inflexible. AI entering the workforce and blending in as a substitute to human capital, will change the nature of labor, potentially dividing labor into a putty, flexible, eternal and exchangeable AI part and a clay labor of inflexible human capital. In order to ensure that human can legally benefit from the economic output and growth generated by AI, a society should be established, in which robots gain quasi-human rights but may not have the same material needs and rights as human beings. In the earliest form of society in the ancient Roman Empire, a society existed that featured a high culture and human protection but legal slavery (Puaschunder, 2019b). A slavery construct thereby would allow to reap the benefits AI. AI's newly assigned roles appear to overlap with slave tasks of ancient Rome slaves that provided manual labor and agriculture, working on farms, mines and mills, household domestic services, urban crafts and services as well as skilled, educated professions, such as accountants and physicians as well as imperial and public services (Hopkins, 1983). Like in ancient Rome, AI could be considered as property with no legal personhood (Johnston, 1957). However, unlike ancient Roman slaves, they should not be subject to corporal punishment, sexual exploitation, torture and summary execution (Kehoe, 2011). Over time in history, AI as the ancient Roman Law example of slaves - may gain more sophisticated legal protection, including the right to file complaints against misuse. AI should be programmed to monitor human conduct towards $\mathrm{AI}$ in order to uphold dignity as a vital social glue within any society.

As for the international character of AI and algorithms, their fungability and fluid capital character; broad legal foundations of AI and the overarching regulatory framework how to classify reaping benefits from AI should be codified in customary international law held in common among all people. This would resemble the ancient tradition of Roman slavery being codified under ius gentium - an ancient predecessor of international law - and allow AI to remain fully fungible and practiced common in all nations that might then have specific civil laws pertaining nuances of AI conduct in society (Puaschunder, 2019b).

As practiced during slavery in the Roman Empire and proposed by Bill Gates, reaping benefits from AI should be taxed based on the revenue generated by AI and/or the price of AI determined by sophistication. Creating a growth theory that addresses AI appears favorable as a guiding standard on how to tax productivity and value gains from AI and AI-holding entities. First codification attempts exist to tax digital transfers - e.g., in the Digitalsteuer proposed by the Austrian government - as well as regulatory guidelines of the European Parliament in the health care sector regarding privacy (Puaschunder, work in progress). 
Defining AI as slaves would not only ensure to uphold decent standards of living for these creatures but also provide the legal ground to account for these production means in taxation. While human naturally stay in charge of the evolution and introduction of AI into human society, AI would become a legal entity that can be measured and monitored for taxation and quality control (Andreoni, Erard \& Feinstein, 1998; Puaschunder, 2015). As debated in the ancient Roman society, sophisticated AI that is used for economic trade may also be permitted to earn money for their personal use; but should never be freed and gain the same rights as human as there is something unique and special to humanness. The uniqueness of human naturally leads to the natural exclusion of AI from the persona, the synonym for the true nature of the individual, and considered to not have a personality. As a Roman Law slave, AI should not own his or her body, have no awareness of its ancestors, and no goods or material cravings of his or her own. The testimony of AI should not be accepted in a court of law unless AI reports misuse that can be harmful to humankind. Differing from Roman Law slavery, AI should never be freed and human should always stay masters of their own creation. AI should not be entitled to hold public office or religious leadership and remain without rights to hold and use property on their own. AI and robots should not be allowed to earn their own money and even if being abandoned by masters, they should never be considered as free.

In order to protect humankind against rebellions of robots and $\mathrm{AI}$, fugitives or deviant developments should be published, stopped according to the right to destroy and those aiding to inform about deviant developments rewarded. While fugitives in the ancient Roman Empire were branded on the forehead or had to wear a metal collar around the neck with the contact of the master; information about stopped AI or robots should be integrated into a blockchain as a trace on unwanted $\mathrm{AI}$ and robot behavior but also as a disciplinary function against other $\mathrm{AI}$ uprising and rebellious tendencies (Puaschunder, 2018b).

If AI gets legally and economically subordinated to human, ethical questions arise. According to Kant's categorical imperative, which states one should only engage in actions, one wants to be done to oneself, AI should be protected against harm and misuse or abuse. The concern here is less so the emotional and psychological state of AI, which arguably may not exists given missing self-cognition and emotions in AI, but more to set a signal and not to allow triggering sadist and negative compulsion in human that could be taken out on other human as well, if human become conditioned and learn from mistreating AI on a daily basis.

In the attempt to protect AI against suffering, harm and misuse or abuse, the Code Napoléon may be applied and define AI and human as quasi-human and grant citizenship to both forms but different power regarding material possession, democratic participation and public leadership. A natural supremacy of human over AI and robots could be established. As the role of woman and minor even differed, a power hierarchy could even be codified between sophisticated and less-sophisticated AI and robots.

Regarding limited space on earth and sustainability concerns, longevity and eternal life of AI appears problematic. Humankind may face tough decisions whether or not to have AI proceed and what kind of developments to flourish and what to extinct (Russell \& Norvig, 1995). In what cases should we consider to switch off AI? In 1950, Isaac Asimov introduced the idea robot to (1) not injure a human being or, through inaction, allow a human being to come to harm. (2) A robot obeying the orders given it by human beings except where such orders conflict with the first law. (3) A robot must protect its own existence as long as such protection does not conflict with the first or second law. So in the cases of overpopulation and harm emerging from AI, algorithms and robots can be considered to be switched off. But when and how to stop AI? 
An economic killing market mechanism may be natural market selection via price mechanisms and the falling rate of profit. Regarding prices, natural supply and demand mechanisms will always favor lucrative innovations with a higher price and following supply of goods lead to a price drop. The falling rate of profit is one of the major underlying features of business cycles, long-term booms and downturns (Brenner, 2002, 2006a, b). Capitalism is thereby described as competitive battle for innovation and reaping benefit from first-market introductions. Once followers enter the market, profit declines, leading eventually to market actors seeking novel ways to innovate in order to regain a competitive market advantage and higher rates of profit. Thereby industries and innovations fade and die off. Such a natural market evolution is also likely to occur with AI innovations, which will determine which AI traits will remain and which ones will fade off (Puaschunder, 2018a). Apart from soft market mechanisms that may lead to AI evolution, what are the cases when AI should be shut down or switched off or - in the case if AI personhood - be killed?

The main and leading concern about any new and emerging technology is to be safe and error free (Meghdari \& Alemi, 2018). Therefore, sufficient and numerus tests on health and safety must be performed by developers and/or well-known independent sources before rolling out any technology onto the marketplace and society (Meghdari \& Alemi, 2018). In robotics, the safety issue mainly centers around software and/or hardware designs (Meghdari \& Alemi, 2018). Even a tiny software flaw or a manufacturing defect in an intelligent machine, like a smart car or a social robot, could lead to fatal results (Meghdari \& Alemi, 2018). When these deviations occur and especially when they are harmful to the human community but also to other AI species, the faulty AI should be terminated. With regard to the risk of robotic malfunctions and errors, product legal responsibility laws are mostly untested in robotics (Meghdari \& Alemi, 2018). A usual way to minimize the risk of damage from social robots is to program them to obey predefined regulations or follow a code-of-ethics (Meghdari \& Alemi, 2018). Ethical codes for robotics are currently needed and should become formed as a natural behavioral law to then be defined and codified as law. Laws but also an ethical understanding to terminate AI, algorithms and robots in case of impairment and harm are needed (Puaschunder, forthcoming a).

As social robots become more intelligent and autonomous and exhibit enough of the features that typically define an individual person, it may be conceivable to assign them responsibility and use them in social, educational, and therapeutic settings (Meghdari \& Alemi, 2018). In the currently ongoing research on the integration of computers and robotics with biological corpse it is found that a cognizant human brain (and its physical body) apparently has human-rights; hence, replacing parts of the brain with artificial ones, while not harming its function, preserves those rights (Meghdari \& Alemi, 2018; Warwick \& Shah, 2014). Also, consider a handicapped person featuring an electronic robot arm that commits a crime (Saffari, Meghdari, Vazirnezhad \& Alemi, 2015). It becomes obvious that half-robot-human beings should be considered as human and robots as quasi-human beings. Meghdari \& Alemi (2018) speculate that at some point in the future, we may face a situation in which more than half of the brain or body is artificial, making the organism more robotic than human, which consolidates the need of special robot-rights and attributing (quasi)-human rights onto robots. When considering robots as quasi-human beings, their termination appears legally questionable and ethically challenging, requiring revisiting laws as legitimation to kill a likewise species as well as ethical consensus on the virtue of killing (Puaschunder, 2018b).

The legal argumentation may draw on justifiable homicide as outlined in criminal law cases such as prevention of greater harm to innocents during an imminent threat to life or well-being in self-defense. According to the United Nations Universal Declaration of Human Rights, Article 
3 states that everyone has the right to life, liberty and security of person. Most nations allows for some degree of leniency for self-defense, which reduces charges. Apart from self-defense, suicide may also serve as legally justified argument for switching off AI, if artificial life is programmed to terminate itself when harmful in such way that AI causes injury to a human being or, through inaction, allow a human being to come to harm (Marra \& McNeil, 2013). The virtue of killing could be grounded on Viktor Mayer-Schönbergers "right to be forgotten," which ensures data privacy through automated deletion of contents after a certain period and grants individuals rights to have their data been destroyed (Puaschunder, 2018a; Puaschunder, forthcoming c, d). In this line, we may argue a "right to destroy" and program AI to stop itself should it incur hurt, damages and losses to humankind. However, the implementation of this right is still in infancy and hindered by questions of what court is responsible for an as such claim. As a legal subsumption, we may speculate that individuals may be granted a 'right to terminate' and can order for robots to be switched off if causing harm to them. As the 'right to be forgotten' law can be overruled by concern for public safety, this may also apply to the right to terminate. Thereby it deserves mentioning that safety and also expected safety standards differ around the world (Puaschunder, 2018b). All these developments are prospected to lead to an AI-evolution, in which human are meant to select the process what AI should survive or be killed. Key decision maker thereby divert favorable traits and developments from unfavorable (Puaschunder, forthcoming b). But who should determine what should survive, human or AI? A question that can be answered by sorting out the legal power relation between $\mathrm{AI}$ and human.

Finally, we may address the question what is it that makes human humane and differing from AI? In the age of artificial intelligence and automated control, humanness is key to future success. Future research may draw from behavioral human decision making insights and evolutionary economics in order to outline what makes human humane and how human decision making is unique to set us apart from artificial intelligence rationality. Humanness as found in heuristics, decision making errors but also procreation and creativity are believed to become more valuable in a future of AI entering the workforce and our daily lives. Drawing from behavioral human decision making insights and evolutionary economics can help to outline what makes human humane and how human decision making is unique to set us apart from AI rationality; AI is argued to bevalue humanness and improve the value of humanimbued unique features (Puaschunder, work in progress). All these humane features of labor should be considered as clay labor, inflexible but valuable and clearly set apart from AI.

In its entirety, the presented work-in-progress futuristic outlook promises to hold novel insights for future success factors of economic growth calculus but also human resource management grounded on efficiency and ethics. Having parts of the world being AI-driven and others being human capital grounded in the future is prospected to increase the international development divide in the years to come. While in the AI-hubs human will be incentivized become more creative and humane while AI performs all rational tasks to a maximum productivity, other parts of the world could naturally fall back as for being stuck in spending human capital time on machine-outsourceable tasks and not honing humane skills, which are not replicable by machines.

Future research endeavors may therefore address inequality drawing on the future vision that central rational AI-hubs will outperform underdeveloped remote areas of the world even more in the digital age. Slowbalisation is projected to draw back outsourcing efforts and divide AI hubs from areas that are less connected. Following research should be concerned with the unprecedentedly high divide between skilled and unskilled labor and the diversion between AI hubs and non-AI territories. In the last four decades, the price of skilled labor has soared 
dramatically relatively to that of unskilled labor despite a major uprise in the relative supply of skills. The notion of skill-bias in growth theories has introduced the theoretical possibility that technological progress benefits only a sub-group of workers, placing technical change at the center of the income distribution debate (Goldberg \& Pavcnik, 2007). Organizational changes have lead to AI technologies reducing costs of communication, monitoring and supervision within the firm, which trigger a shift towards a new organizational design. The change towards AI induces an organizational shift towards skill-biased meritocracy. Endogenous technical progress leads to economic growth, but also generates wage inequality between lowand high skilled workers (Duarte \& Restuccia, 2006; Murphy, Riddell \& Romer, 1998; Parente $\&$ Prescott, 1993). Faster technical change increases the return to ability and increases wage inequality between, and also within, groups of high-skilled and unskilled workers (Galor \& Moav, 2000). Future studies should integrate some of the contemporary inequality measurements such as the Palma ratio, financial development and wealth transfers in contemporary growth theories and measurement (Jacoby, 2008; Milanovic, 2013; Piketty, 2014). Wage inequality is only one way to assess inequality, but in order to get a richer picture of inequality derived from AI, future research may also consider inequality in wealth, health, status and within-group inequalities (Restuccia \& Urrutia, 2001). Understanding the links between growth and inequality should also be placed in the different contexts of political, social and historical environments in order to derive inference about a successful introduction of AI into today's workforce and society. Finally, more research is recommended to model and maximize the novel production function including AI and information share - especially in light of G5 and the internet of things leading to a further connection and benefits from technology. All these novel developments may lead to a potential polarization between more efficient AI hubs and low skill low labor cost areas that may be shunned from economic growth due to a predicted reshoring trend coupled with AI economic dominance and unprecedented technology gains (Aghion \& Bolton, 1997; Matsuyama, 2000, 2011; Restuccia \& Rogerson, 2017; Ventura, 1997).

Overall, the presented work-in-progress captures AI's entrance into the workforce and our daily lives. The currently ongoing market transition of AI encroaching conventional markets will likely lead to a re-ordering of the current global economic and political order. The results on slowbalisation mark the very first attempt to describe slowbalisation in light of the currently ringing in AI market disruption. The findings on the relation of AI and GDP appear as first trace of AI shaping economies as if guided by an artificial drive. Depicting growth during this unprecedented time of economic change and regulatory reform of shaping a novel technology revolution holds invaluable historic opportunities for outlining technology-driven market changes' influence on the stability of economies and society. As never before in history, automatization may enrich the world economy in very many novel ways regardless of national borders - but only if also be safeguarded by ethical imperatives. The presented research aims at the current creative destruction in the wake of AI entering the world economies being ennobled by a social face and lowering potential societal downfalls (Schumpeter, 1942/1975). The findings may also bestow global governance policy makers with ideas how to better snapshot AI's potential in the digitial age and market actors with future-oriented foresight how to benefit from this new technology (Banerjee, 2008; Klenow, 2008). Market and societal policy recommendations may aid global governance experts to strengthen society through AI but also overcome unknown emergent risks within globalized markets in the wake of the AI revolution. At the same time of acknowledging the potential of AI, ethical considerations appear necessary as we have to become aware of the risk imbued in the artificial age, such as legal regulatory gaps and crowding out humanness or reverting the past accomplishments of outsourcing helping nations to develop out of poverty. Conventional economic policies may therefore be coupled with a holistic vision that encompasses socio-economic and political 
values. Drawing attention to potential international development drawbacks and a further disparity of society based on skills and access to refined technology will offer market actors and governance bodies key insights - not only on how to benefit from a digitalizing world but also how to administer the current market transition so the benefits get distributed equally around the world. Societies of tomorrow should therefore be built on AI ethics in order to safeguard the transition to artificiality enhancing economies and ennoble society through a mutual understanding and exchange of putty and clay labor.

\section{References}

Acemoglu, D. (2009a). Economic growth and economic development: The questions. In D. Acemoglu (Ed.), Introduction to Modern Economic Growth, pp. 3-25, Princeton, NJ: Princeton University Press.

Acemoglu, D. (2009b). The Solow model and the data. In D. Acemoglu (Ed.), Introduction to Modern Economic Growth, pp. 77-107, Princeton, NJ: Princeton University Press.

Aghion, P. \& Bolton, P. (1997). A theory of trickle-down growth and development. Review of Economic Studies, 64, 2, 151-172.

Aghion, P. \& Howitt, P. (1992). A model of growth: Through creative destruction. Econometrica, 60, 2, 323-351.

Aghion, P. \& Howitt, P. (1998). Endogenous growth theory. Cambridge, MA: MIT Press.

Aghion, P., Jones, B.F. \& Jones, Ch.I. (2017). Artificial Intelligence and economic growth. National Bureau of Economic Research working paper retrieved at https://www.nber.org/chapters/c14015

Alemi, M., Meghdari, A., Saffari, E. (2017). RoMa: A hi-tech robotic mannequin for the fashion industry." Lecture Notes in Computer Science (LNCS): Social Robotics, 10652, 209-219, Springer, Nov. 2017.

Alvarez, F., Buera, F. \& Lucas, R.E. (2007). Idea flows, economic growth, and trade. National Bureau of Economic Research working paper retrieved at https://www.nber.org/papers/w19667

Andreoni, J., Erard, B. \& Feinstein, J.S. (1998). Tax compliance. Journal of Economic Literature, 36, 2, 818-860.

Armstrong, St. \& Sotala, K. (2012). How we're predicting AI - or failing to. In J. Ramportl (Ed.), Beyond AI: Artificial dreams, p. 52-65. Pilsen: University of West Bohemia.

Arrow, K. (1962). The economic implications of learning by doing. Review of Economic Studies, 29, 3, 155-173.

Arrow, K. (1969). Classificatory notes on the production and transmission of technological knowledge. American Economic Review, 59, 2, 29-35.

Asimov, I. (1942). Runaround. London: Grafton Books.

Asimov, I. (1950). I, Robot. New York: Bantam Dell.

Asimov, I. (1978). My own view. In R. Holdstock, The Encyclopedia of Science Fiction. New York: St. Martin's.

Asimov, I. (1985). Robots and empire. New York: Doubleday.

Baldwin, R. (2017). The great conversion: Information technology and the new globalization. Cambridge, MA: Harvard University Press.

Banerjee, A. (2008). Big answers for big questions: The presumption of growth policy. In Brookings Institute (Ed.), What Works in Development? Thinking Big and Thinking Small, pp. 207-231. Washington, DC: Brookings Institute.

Banerjee, A. \& Duflo, E. (2005). Growth theory through the lens of development economics. In P. Aghion \& S. Durlauf (Eds.), Handbook of Economic Growth, pp. 473-552. Amsterdam: Elsevier.

Banerjee, A. \& Moll, B. (2010). Why does misallocation persist? American Economic Journal: Macroeconomics, 2, 1, 189-206.

Banerjee, A. \& Newman, A.F. (1993). Occupational choice and the process of development, Journal of Political Economy, 101, 2, 274-298.

Barro, R.J. (1990). Government spending in a simple model of endogenous growth. Journal of Political Economy, 98, 103-125.

Barro, R.J. (1991). Economic growth in a cross section of countries. The Quarterly Journal of Economics, 106, 2, 1, 407-444. 
Barseghyan, L. \& DiCecio, R. (2011). Entry costs, industry structure, and cross-country income and TFP differences. Journal of Economic Theory, 146, 5, 1828-1851.

Bartelsman, E.J., Haltiwanger, J. \& Scarpetta, S. (2013). Cross-country differences in productivity: The role of allocation and selection. American Economic Review, 1, 103, 305-334.

Bils, M. \& Klenow, P. (2002). Does schooling cause growth? American Economic Review, 90, 5, 1160-1183.

Bjork, G.J. (1999). The way it worked and why it won't: Structural change and the slowdown of U.S. economic growth. Westport, CT: Praeger.

Buera, F.J. \& Kaboski, J.P. (2012). The rise of the service economy. American Economic Review, 102, 6, 2540-2569.

Burmeister, E. (2000). The capital theory controversy. In H. Kurz (Ed)., Critical Essays on Piero Sraffa's Legacy in Economics, pp. 305-314. Cambridge, UK: Cambridge University Press.

Beerbaum, D. \& Puaschunder, J.M. (2018). A behavioral economics approach to digitalisation: The case of a principles-based taxonomy. Proceedings of the 10th International RAIS Conference on Social Sciences and Humanities; Published by Atlantis Press; Part of Series: ASSEHR; ISSN: 2352-5398, Volume 211.

Brenner, R. (2002). American economic revival, In R. Brenner, The Boom and the Bubble: The US in the World Economy. New York: Verso.

Brenner, R. (2006a). The puzzle of the long downturn, In R. Brenner, The Economics of Global Turbulence: The Advanced Capitalist Economies from Long Boom to Long Downturn, 1945-2005. New York: Verso.

Brenner, R. (2006b). From boom to downturn, In R. Brenner, The Economics of Global Turbulence: The Advanced Capitalist Economies from Long Boom to Long Downturn, 1945-2005. New York: Verso.

Buera, F.J. \& Shin, Y. (2011). Finance and development: A tale of two sectors. American Economic Review, 101, 1964-2002.

Căpek, K. (1921/2004). Rossum's universal robots. New York: Penguin.

Caselli, F. (2005). Accounting for cross-country income differences. In P. Aghion \& St. Durlauf (Ed.), Handbook of Economic Growth, pp. 679-741. Amsterdam: Elsevier.

Caselli, F. \& Feyrer, J. (2007). The marginal product of capital. The Quarterly Journal of Economics, 122, 2, 535-568.

Cellan-Jones, R. (2014). Stephen Hawking warns Artificial Intelligence could end mankind. BBC News, 2 December, 2014. www.bbc.com/news/technology-30290540

Centeno, M.A., Creager, A.N., Elga, A., Felton, E., Katz, St.N., Massey, W.A. \& Shapiro, J.N. (2013). Global systemic risk: Proposal for a research community. Princeton University, NJ: Princeton Institute for International and Regional Studies working paper.

Centeno, M.A. \& Tham, A. (2012).The emergence of risk in the global system. Princeton, NJ: Princeton University working paper.

Clancy, E. (1998). The tragedy of the global commons. Indiana Journal of Global Legal Studies, 5, 2, 601-619.

Comin, D. \& Hobijn, B. (2004). Cross-country technology adoption: Making the theories face the facts. Journal of Monetary Economics, 51, 1, 39-83.

Comin, D. \& Hobijn, B. (2010). An exploration of technology diffusion. American Economic Review, 100, 5, 20312059.

Copeland, J. (2000). What is Artificial Intelligence? AlanTuring.net, May.

www.alanturing.net/turing_archive/pages/Reference\%20Articles/what_is_AI/What\%20is\%20AI02.html

Deaton, A. (2010). Understanding the mechanisms of economic development. Journal of Economic Perspectives, 24, 3, 3-16.

Dillon, M. \& Garland, L. (2005). Ancient Rome: From the early republic to the assassination of Julius Caesar. London, UK: Routledge.

Dowell, R. (2018). Fundamental protections for non-biological intelligences or: How we learn to stop worrying and love our robot Brethren. Minnesota Journal of Law, Science \& Technology, 19, 1, 305-336.

Dray, M. \& Thirlwall, A.P. (2011). The endogeneity of the natural rate of growth for a selection of Asian countries. Journal of Post Keynesian Economics, 33, 3, 451-468.

Duarte, M. \& Rstuccia, D. (2006). The productivity of nations. Federal Reserve Bank Richmond Economic Quarterly, $92,3,195-223$. 
Echevarria, C. (1997). Changes in sectoral composition associated with economic growth. International Economic Review, 38, 2, 431-452.

Erosa, A., Koreshkova, T. \& Restuccia, D. (2010). How important is human capital? A quantitative theory assessment of world income inequality. The Review of Economic Studies, 77, 4, 1421-1449.

EU Committee on Legal Affairs. (2016). Draft report with recommendations to the Commission on Civil Law Rules on Robotics. May 31.

Foster, A.D. \& Rosenzweig, M.R. (2010). Microeconomics of technology adoption. Yale University Economic Growth Center Discussion Paper 984.

Futagami, K., Morita, Y. \& Shibata, A. (1993). Dynamic analysis of an endogenous growth model with public capital. Scandinavian Journal of Economics, 95, 607-625.

Galeon, D. \& Reedy, Ch. (2017). Kurzweil claims that the singularity will happen by 2045. Futurism, October 5, futurism.com/kurzweil-claims-that-the-singularity-will-happen-by-2045/.

Galor, O. \& Moav, O. (2000). Ability biased technological transition, wage inequality and growth. Quarterly Journal of Economics, 115, 469-498.

Galor, O. \& Moav, O. (2004). From physical to human capital accumulation: Inequality in the process of development. Review of Economic Studies, 71, 1001-1026.

Galor, O. \& Tsiddon, D. (1997). The distribution of human capital and economic growth. Journal of Economic Growth, 2, 1, 93-124.

Gamauf, R. (2009). Slaves doing business: The role of Roman Law in the economy of a Roman household. European Review of History, 16, 3, 331-346.

Goldberg, K. \& Pavcnik, N. (2007). The distributional effects of globalization in developing countries. Journal of Economic Literature, 45, 1, 39-82.

Garegnani, P. (2008). On Walras's theory of capital. Journal of the History of Economic Thought, 30, 3, 367-384.

Greenwood, J. \& Jovanovic, B. (1990). Financial development, growth, and the distribution of income. Journal of Political Economy, 98, 5, 1, 1076-1107.

Grossman, G.M. \& Helpman, E. (1991a). Innovation and growth in the global economy. Cambridge, MA: MIT Press.

Grossman, G.M. \& Helpman, E. (1991b). Quality ladders in the theory of growth. Review of Economic Studies, 58, 1, 43-61.

Hagey, K., Alpert, L.I. \& Serkez, Y. (2019). In news industry, a stark divide between haves and have-nots: Local newspapers are failing to make the digital transition larger players did and are in danger of vanishing. The Wall Street Journal, May 4, 2019.

Hall, R.E. \& Jones, Ch.I. (1999). Why do some countries produce so much more output per worker than others? The Quarterly Journal of Economics, 114, 1, 83-116.

Harberger, A. (1998). A vision of the growth process. American Economic Review, 88, 1, 1-32.

Harris, W.V. (2000). Trade. In: The Cambridge Ancient History: The High Empire A.D. 70-192, p. 11. Cambridge, UK: Cambridge University Press.

Harrod, R.F. (1939). An essay in dynamic theory. The Economic Journal, 49, 193, 14-33.

Hausmann, R., Pritchett, L. \& Rodrik, D. (2005). Growth accelerations. Journal of Economic Growth, 10, 4, 303-329.

Hayes, A. (2018). Decentralized banking: Monetary technocracy in the digital age. Social Science Research Network working paper retrievable at https://papers.ssrn.com/sol3/papers.cfm?abstract_id=2807476

Held, D. \& McGrew, A.G. (2007). A new world economic order? Global markets and state power: Beyond globalization/anti-globalization: Beyond the great divide. New York, NY: Polity.

Hopkins, K. (1983). Conquerors and slaves: Sociological studies in Roman history. New York: Cambridge University Press.

Hsieh, C.T. (2002). What explains the industrial revolution in East Asia? Evidence from the factor markets. American Economic Review, 92, 3, 502-526.

Hsieh, C.T. \& Klenow, P. (2005). Relative prices and relative prosperity. American Economic Review, 98, 3, 562-585. 
Hsieh, C.T. \& Klenow, P. (2010). Development accounting. American Economic Journal: Macroeconomics, 2, 1, $207-$ 223.

Jacoby, H.G. (2008). Food prices, wages, and welfare in rural India. Economic Inquiry, 54, 1, 159-176.

Johnston, M. (1957). Roman life. Chicago, IL: Scott, Foresman.

Jones, B.F. (2014). The human capital stock: A generalized approach. American Economic Review, 104, 11, 3752 3777.

Jones, B.F. \& Olken, B.A. (2008). The anatomy of start-stop growth. Review of Economics and Statistics, 90, 3, 582587.

Jones, Ch.I. (1999). Growth: With or without scale effects. American Economic Review, 89, 2, 139-144.

Jones, Ch.I. (2004). Growth and ideas. National Bureau of Economic Research working paper retrieved at https://www.nber.org/papers/w10767

Jones, Ch.I. (2016). The facts of economic growth. In J.B. Taylor \& H. Uhlig (Eds.), Handbook of Economic Growth, pp. 3-69.

Kahneman, D. \& Tversky, A. (1979). Prospect theory: An analysis of decision under risk. Econometrica, 47, 2, 263291.

Kaldor, N. (1961). Capital accumulation and economic growth. In F.A. Lutz \& D.C. Hague (Eds.), The Theory of Capital, pp. 177-222, New York: St. Martins.

Kehoe, D.P. (2011). Law and social function in the Roman Empire. The Oxford Handbook of Social Relations in the Roman World. Oxford, UK: Oxford University Press.

Kirchler, E.M. (2007). The economic psychology of tax behaviour. Cambridge, UK: Cambridge University Press.

Kirchler, E.M. (2011). Wirtschaftspsychologie: Individuen, Gruppen, Märkte, Staat. Göttingen: Hogrefe.

Klenow, P. (2008). Discussion of 'Big Answers for Big Questions: The Presumption of Growth Policy' by A.V.

Banerjee. In Brookings Institute (Ed.), What Works in Development? Thinking Big and Thinking Small. Washington, DC: Brookings Institute.

Klenow, P. \& Rodríguez-Clare, A. (1997). Economic growth: A review essay. Journal of Monetary Economics, 40, 4, 597-618.

Kortum, S.S. (1997). Research, patenting, and technological change. Econometrica, 65, 6, 1389-1420.

Kowert, W. (2017). The foreseeability of human-artificial intelligence interactions. Texas Law Review, 96, 181-204.

Kremer, M. (1993). Population growth and technological change: One million B.C. to 1990. Quarterly Journal of Economics, 108, 3, 681-716.

Kremer, M., Rao, G. \& Schilbach, F. (2019). Behavioral development economics. In D. Bernheim, St. DellaVigna \& D. Laibson (Eds.), Handbook of Behavioral Economics: Foundations and Applications, pp. 345-458. North Holland:

Elsevier.

Krueger, A.0. (1997). Trade policy and economic development: How we learn. American Economic Review, 87, 1, 122.

Kuznets, S. (1973). Modern economic growth: Findings and reflections. American Economic Review, 63, 3, 247-258.

Larson, D.A. (2010). Artificial Intelligence: Robots, avatars, and the demise of the human mediator. Ohio State Journal on Dispute Resolution, 25, 105-164.

Laton, D. (2016). Manhattan_Project.Exe: A nuclear option for the digital age. Catholic University Journal of Law \& Technology, 25, 4, 94-153.

Lin, P., Abney, K. \& Bekey, G.A. (2012). Robot ethics: The ethical and social implications of robotics. London,

England: The MIT Press.

Lucas, R.E. (1988). On the mechanics of economic development. Journal of Monetary Economics, 22, 3-42.

Lucas, R.E. (1999). Why doesn't capital flow from rich to poor countries? American Economic Review, 80, 5, 92-96.

Lucas, R.E. (2004). The industrial revolution: Past and future. Annual Report of the Federal Reserve Bank of Minneapolis, May, pp. 5-20.

Lucas, R.E. (2009). Ideas and Growth. Economica, 76, 1-19. 
Lucas, R.E. \& Moll, B. (2014). Knowledge growth and the allocation of time. Journal of Political Economy, 122, 1, 151.

MacDonald, F. (2016). Harvard scientists think they've pinpointed the physical source of consciousness. Science Alert, June 23. http://www.sciencealert.com/harvard-scientists-think-they-ve-pinpointed-the-neural-source-ofconsciousness.

Mankiw, N.G., Romer, D. \& Weil, D.N. (1992). A contribution to the empirics of economic growth. The Quarterly Journal of Economics, 107, 2, 407-437.

Manuelli, R.E. \& Seshadri, A. (2014). Human capital and the wealth of nations. American Economic Review, 9, 27362762.

Marra, W. \& McNeil, S. (2013). Understanding "The loop": Regulating the next generation of war machines. Harvard Journal of Law \& Public Policy, 36, 1139-1187.

Matsuyama, K. (2000). Endogenous inequality. Review of Economic Studies, 67, 4, 743-759.

Matsuyama, K. (2008). Structural change. In S. Durlauf \& L.E. Blume (Eds.), The New Palgrave Dictionary of Economics, pp. London: Palgrave-Macmillan.

Matsuyama, K. (2011). Imperfect credit markets, household wealth distribution, and development. Annual Review of Economics, 3, 339-362.

Mauss, M. (1979). A category of the human mind: The notion of the person, the notion of 'self,' In M. Mauss (Ed.), Sociology and Psychology, pp 81-103, London, UK: Routledge.

Meghdari, A. \& Alemi, M. (2018). Recent advances in social \& cognitive robotics and imminent ethical challenges. Proceedings of the 10th International RAIS Conference on Social Sciences and Humanities organized by Research Association for Interdisciplinary Studies (RAIS) at The Erdman Center at Princeton University, Princeton, New Jersey, United States. Cambridge, MA: The Scientific Press.

Meghdari, A., Alemi, M., Zakipour, M., Kashanian, S.A. (2018). Design and realization of a sign language educational humanoid robot. Journal of Intelligent \& Robotic Systems, 1-15.

Meghdari, A., Shariati, A., Alemi, M., Vossoughi, G.R. (2018). Arash: A social robot buddy to support children with cancer in a hospital environment. Journal of Engineering in Medicine, 232, 6, 605-618.

Milanovic, B. (2013). Global income inequality in numbers: In history and now. Global Policy, 4, 2, 198-208.

Mohamed, A.M.I. (2016). Globalization and new international public works agreements in developing countries: An analytical perspective. London, UK: Routledge.

Moll, B. (2014). Productivity losses from financial frictions: Can self-financing undo capital misallocations? American Economic Review, 104, 10, 3186-3221.

Mookherjee, D. \& Napel, S. (2007). Intergenerational mobility and macroeconomic history dependence. Journal of Economic Theory, 137, 1, 49-78.

Mookherjee, D. \& Ray, D. (2003). Persistent inequality. Review of Economic Studies, 70, 369-393.

Mumford, A. (2001). Taxing culture. Aldershot, UK: Ashgate.

Murphy, K.M., Riddell, W.C. \& Romer, P.M. (1998). Wages, skills, and technology in the United States and Canada. National Bureau of Economic Research (NBER) Working Paper 6638 retrieved at https://www.nber.org/papers/w6638.pdf

Ngai, L.R. \& Pissarides, Ch.A. (2007). Structural change in a multi-sector model of growth. American Economic Review, 97, 1, 429-443.

Noyes, K. (2016). 5 things you need to know about A.I.: Cognitive, neural and deep, oh my! Computerworld, March 3. www.computerworld.com/article/3040563/enterprise-applications/5-things-you-need-toknow-about-aicognitive-neural-anddeep-oh-my.html [http://perma.cc/7PW9-P42G.

Parente, St. \& Prescott, E. (1993). Changes in the wealth of nations. Quarterly Review of Economics, 17, 2, 3-16.

Petri, F. (2009). On the recent debate on capital theory and general equilibrium. Quaderni del Dipartimento di Economia Politica, Università di Siena.

Piketty, Th. (1997). The dynamics of the wealth distribution and the interest rate with credit rationing. Review of Economic Studies, 64, 2, 173-189.

Piketty, Th. (2014). Capital in the twenty-first century. Cambridge, MA: Harvard University Press. 
Pritchett, L. (1997). Divergence, big time. Journal of Economic Perspectives, 11, 3, 3-17.

Profita, S. (2019). Slowbalization and its risks. Columbia University working paper. New York, NY: Columbia University.

Puaschunder, J.M. (2015). Trust and reciprocity drive common goods allocation norms. Proceedings of the Cambridge Business \& Economics Conference. Cambridge, UK: Cambridge University.

Puaschunder, J.M. (2017). Nudgital: Critique of Behavioral Political Economy. Archives of Business Research, 5, 9, 54-76.

Puaschunder, J.M. (2018a). Artificial Intelligence Evolution: On the virture of killing in the artificial age. Social Science Research Network working paper retrievable at

https://papers.ssrn.com/sol3/papers.cfm?abstract_id=3247401

Puaschunder, J.M. (2018b). Gifts without borders: Intergenerational glue connecting over distance and time as pure international development in the age of migration. In J. M. Puaschunder (Ed.), Intergenerational Responsibility in the $21^{\text {st }}$ Century, pp. 143-174. Wilmington, DE: Vernon.

Puaschunder, J.M. (2019a). Towards a utility theory of privacy and information sharing and the introduction of hyper-hyperbolic discounting in the digital big data age, Research Association for Interdisciplinary Studies Collective Volume: Economic Science, 2019, pp. 4-46.

Puaschunder, J.M. (2019b). On Artificial Intelligence's razor's edge: On the future of democracy and society in the artificial age. Journal of Economics and Business, 2, 1, 100-119.

Puaschunder, J.M. (forthcoming a). Artificial Intelligence Ethics. Report to the European Parliament.

Puaschunder, J.M. (forthcoming b). Artificial Intelligence Evolution: On the Virtue of Killing in the Artificial Age. Journal of Sociology.

Puaschunder, J.M. (forthcoming c). Dignity and utility of privacy and information sharing in the digital big data age. Humanistic Management Journal.

Puaschunder, J.M. (forthcoming d). Towards a utility theory of privacy and information sharing and the introduction of hyper-hyperbolic discounting in the digital big data age, In E. Idemudia (Ed.), Optimizing Social and Organizational Dynamics in the Digital Era, Hershey, PA: IGI.

Puaschunder, J.M. (work in progress). Big data health care ethics study. Working paper on behalf of the European Liberal Forum of the European Parliament.

Rajan, R.G. \& Zingales, L. (1998). Financial dependence and growth. American Economic Review, 88, 3, 559-586.

Restuccia, D. \& Rogerson, R. (2017). The causes and costs of misallocation. Journal of Economic Perspectives, 31, 3, 151-174.

Restuccia, D. \& Urrutia, C. (2001). Relative prices and investment rates. Journal of Monetary Economics, 47, 1, 93121.

Rodrik, D. (2006). Goodbye Washington consensus, hello Washington confusion? A review of the World Bank's economic growth in the 1990s: Learning from a decade of reform. Journal of Economic Literature, 44, 4, 973-987.

Romer, P.M. (1986). Increasing returns and long-term growth. The Journal of Political Economy, 94, 5, 1002-1037.

Romer, P.M. (1990). Endogenous technological change. Journal of Political Economy, 98, 5, 71-102.

Russell, St. \& Norvig, P. (1995). Artificial intelligence a modern approach. New York, NY: Simon \& Schuster.

Saffari, E., Meghdari, A., Vazirnezhad, B. \& Alemi, M. (2015). Ava (a social robot): Design and performance of a robotic hearing apparatus. LNCS: Social Robotics, 9388, 440-450, Springer, Oct. 2015.

Schefold, B. (2005). Zero wages - no problem? A reply to Mandler. Metroeconomica: International Review of Economics, 56, 4, 503-513.

Schuller, A. (2017). At the crossroads of control: The intersection of Artificial Intelligence in autonomous weapon systems with International Humanitarian Law. Harvard National Security Journal, 8, 379-425.

Schumpeter, J.A. (1942/1975). Capitalism, socialism and democracy. New York: Harper.

Sofge, E. (2015). Bill Gates fears A.I., but A.I. researchers know better. Popular Science. www.popsci.com/ billgates-fears-ai-ai-researchers-know-better.

Solow, R. (1956). A contribution to the theory of economic growth. The Quarterly Journal of Economics, 70, 1, 6594. 
Solum, L. (1992). Legal personhood for Artificial Intelligences. North Carolina Law Review, 70, 4, 1231-1287.

Stiglitz, J. (1998). The private uses of public interests: Incentives and institutions. Journal of Economic Perspectives, $12,3-22$.

Stroebe, W. \& Frey, B.S. (1982). Self-interest and collective action: The economics and psychology of public goods. British Journal of Social Psychology, 21, 2, 121-137.

Swiecki, T. (2017). Determinants of structural change. Review of Economic Dynamics, 17, 24, 95-131.

Taheri, A.R., Meghdari, A., Alemi, M. \& Pouretemad, H.R. (2018). Human-robot interaction in autism treatment: A case study on three pairs of autistic children as twins, siblings, and classmates. International Journal of Social Robotics, 10, 1, 93-113.

Tcherneva, P. (2011). Bernanke's paradox: Can he reconcile his position on the federal budget with his charge to prevent deflation? Journal of Post Keynesian Economics, 3, 33, 411-434.

The Economist (2019). The steam has gone out of globalisation: Slowbalisation, January 26, pp. 17-20.

Themistoklis, T. (2018). Artificial intelligence as global commons and the "international law supremacy" principle. Proceedings of the 10th International RAIS Conference on Social Sciences and Humanities organized by Research Association for Interdisciplinary Studies (RAIS) at The Erdman Center at Princeton University, Princeton, New Jersey, United States. Cambridge, MA: The Scientific Press.

The Oxford Encyclopedia of Ancient Greece and Rome. (2010). Oxford, UK: Oxford University Press.

Townsend, R.M. \& Ueda, K. (2006). Financial deepening, inequality, and growth: A model-based quantitative evaluation. Review of Economic Studies, 73, 1, 251-293.

Tybout, J. (2000). Manufacturing firms in developing countries: How well do they do, and why? Journal of Economic Literature, 38, 1, 11-44.

United Nations Department of Economic and Social Affairs (2017). Will robots and AI cause mass unemployment? Not necessarily, but they do bring other threats. New York:

https://www.un.org/development/desa/en/news/policy/will-robots-and-ai-cause-mass-unemployment-notnecessarily-but-they-do-bring-other-threats.html

Uzawa, H. (1965). Technical change in an aggregative model of economic growth. International Economic Review, $6,1,18-31$.

Van Neuss, L. (2019). The drivers of structural change. Journal of Economic Survey, 33, 1, 309-349.

Ventura, J. (1997). Growth and interdependence. The Quarterly Journal of Economics, 112, 1, 57-84.

Veruggio, G. (2005). The birth of roboethics. ICRA 2005, IEEE Int. Conference on Robotics and Automation: Workshop on Robo-Ethics, Barcelona, April 18, 2005.

Vlassopoulos, K. (2009). Politics antiquity and its legacy. Oxford, UK: Oxford University Press.

Warwick, K. \& Shah, H. (2014). How good robots will enhance human life. In K. Tchon and W.W. Gasparski (Eds.), Treatise on Good Robots Edition: Praxology: The International Annual of Practical Philosophy and Methodology, pp. 3-19. London, UK: Transaction.

Wisskirchen, G., Biacabe, B.T., Bormann, U., Muntz, A., Niehaus, G., Jiménez-Soler, G. \& von Brauchitsch, B. (2017). Artificial Intelligence and robotics and their impact on the workplace. London: IBA Global Employment Institute.

World Bank Group Migration and Development Brief 26 (2016). Migration and remittances: Recent development and outlook. Washington D.C.: International Bank for Reconstruction and Development, World Bank Group, April 2016.

World Bank 2008 Report (2008). Technology diffusion in the developing world: Global Economic Prospects Report. Washington, DC: World Bank.

World Bank 2015 Report (2015). Washington, D.C.: World Bank. 
APPENDIX

Table A1: AI-GDP-Index for 191 countries of the world

\begin{tabular}{|c|c|c|c|c|c|c|}
\hline Luxembourg & 102228.64 Aruba & 24929.06 Kazakhstan & $6900.00 \mathrm{Fiii}$ & 2792.81 Micronesia & 1125.34 Pakistan & 240.07 \\
\hline Switzerland & 75300.00 Spain & 23900.00 Romania & 6900.00 Jordan & 2758.27 Egypt, Arab Rep. & 1080.00 Mauritania & 236.46 \\
\hline Norway & 73100.00 Bahrain & 22760.66 Lebanon & 6886.62 Armenia & 2744.66 Diibouti & 1073.31 Kiribati & 232.48 \\
\hline Iceland & 70070.96 Malta & 21417.66 Turkey & 6820.00 Suriname & 2602.61 Esmatini & $982.55 \mathrm{Nepal}$ & 181.72 \\
\hline Macao & 67281.87 Cyprus & 20717.73 Brazil & 6620.00 Equatorial Guinea & 2544.66 Sudan & 894.79 Tajikistan & 175.91 \\
\hline Qatar & 60700.00 Italy & 19700.00 Grenada & 6173.60 Jamaica & 2494.68 Mongolia & 881.57 Riwanda & 162.89 \\
\hline Ireland & 58200.00 Slovenia & 18618.07 Mauritius & 5828.18 Iraq & 2476.87 Vanuatu & 803.39 Tanzania & 153.35 \\
\hline Denmark & 55600.00 Estonia & 17797.03 Mexico & 5690.00 Georgia & 2447.12 Uzbekistan & 802.28 Uganda & 143.77 \\
\hline Sweden & 51300.00 Saudi Arabia & 17100.00 Montenegro & 5547.88 Belize & 2340.57 Honduras & 797.02 Congo, Rep. & 143.07 \\
\hline Singapore & 48700.00 Czech Riepublic & 16000.00 Bulgaria & 5217.39 West Bank and Gaza & 2017.76 Ghana & 775.15 Ethiopia & 142.91 \\
\hline Australia & 46600.00 Portugal & 15700.00 Nauru & 5041.50 Algeria & 1933.99 India & 682.00 Gambia, The & 140.66 \\
\hline Netherlands & 45200.00 St. Kitts and Nevis & 14466.55 St. Lucia & 4936.80 Namibia & 1926.88 Cote d'lvoire & 674.04 Benin & 116.82 \\
\hline United States & 45100.00 Slovak Republic & 14349.19 China & 4790.00 Tunisia & 1922.75 Lao PDR & 626.89 Comoros & 111.26 \\
\hline Austria & 41700.00 Barbados & 13373.59 St. Vincent \& Grenadines & 4684.31 Morocco & 1867.03 Timor-Leste & $626.63 \mathrm{Mali}$ & 105.20 \\
\hline Canada & 41600.00 Greece & 13200.00 Dominica & 4677.98 Cabo Verde & 1854.57 Nicaragua & 619.06 Burkina Faso & 101.93 \\
\hline Hong Kong & 41300.00 Lithuania & 13046.85 Dominican Republic & 4583.49 Guatemala & 1819.83 Angola & 587.94 Haiti & 94.38 \\
\hline Finland & 40100.00 Latvia & 12754.03 Belarus & 4267.67 Philippines & 1800.00 Sao Tome and Principe & 575.06 Guinea & 93.88 \\
\hline Andorra & 38704.75 Chile & 12600.00 Serbia & 4150.38 Tuvalu & 1750.79 South Asia & 565.00 Mozanbique & 88.54 \\
\hline New Zealand & 38700.00 Trinidad and Tobago & 12469.89 Cuba & 4141.04 Moldova & 1743.43 Nigeria & 545.00 Togo & 75.42 \\
\hline United Arab Emirates & 38600.00 Dman & 12242.30 North Macedonia & 4132.00 Guyana & 1737.57 Cambodia & 470.70 Sierra Leone & 66.12 \\
\hline Belgium & 38100.00 Antigua and Barbuda & 11250.29 Colombia & 3990.00 Tonga & 1633.07 Kyrgyz Republic & 466.21 Afghanistan & 62.97 \\
\hline United Kingdom & 37800.00 Uruguay & 11092.44 Gabon & 3730.63 Ukraine & 1507.74 Zambia & 421.49 Liberia & 55.44 \\
\hline Germany & 37700.00 Hungary & 11000.00 Ecuador & 3592.97 Bhutan & 1505.84 Senegal & 394.05 Malawi & 46.65 \\
\hline Japan & 34900.00 Argentina & 10900.00 Bosnia and Herzegovina & 3577.55 Bolivia & 1487.65 Myanmar & 385.52 Madagascar & 44.07 \\
\hline Israel & 33100.00 Poland & 10500.00 Paraguay & 3556.91 Marshall Islands & 1487.33 Zimbabwe & 360.76 Chad & 43.06 \\
\hline France & 31000.00 Seychelles & 9185.31 Thailand & 3490.00 Samoa & 1438.83 Lesotho & 343.88 Congo, Dem. Rep. & 39.89 \\
\hline San Marino & 29421.94 Croatia & 8981.84 South Africa & 3450.00 Turkmenistan & 1399.72 Cameroon & 336.88 Niger & 38.65 \\
\hline Guam & 28720.96 Panama & 8793.41 Iran, Islamic Rep. & 3380.00 Sri Lanka & 1389.69 Yemen, Rep. & 295.72 Guinea-Bissau & 28.44 \\
\hline Kumait & 28500.00 Costa Rica & 8358.78 Azerbaijan & 3266.76 Libya & 1300.76 Kenya & 284.31 Central African Republic & 18.16 \\
\hline Korea, Rep. & 28300.00 Russian Federation & 8170.00 Albania & 3260.12 Indonesia & 1240.00 Papua New Guinea & 278.99 Burundi & 16.34 \\
\hline Brunei Darussalam & 26838.34 Malaysia & 7980.00 Peru & 3200.00 El Salvador & 1215.46 Bangladesh & 273.28 Somalia & 9.59 \\
\hline Bahamas, The & 26147.71 Maldives & 7045.88 Botswana & 3145.63 Vietnam & 1160.00 Solomon Islands & 254.24 & \\
\hline
\end{tabular}

\begin{tabular}{|c|c|c|c|c|c|c|}
\hline Afghanistan & 62.97012 Canada & 41595.83 Germany & 37695.68 Lebanon & 6886.623 North Macedonia & 4132 St. Kitts and Nevis & 14466.55 \\
\hline Albania & 3260.116 Central Africa & 18.15593 Ghana & 775.1514 Lesotho & 343.8836 Norway & 73061.05 St. Lucia & 4936.8 \\
\hline Algeria & 1933.99 Chad & 43.06249 Greece & 13199.06 Liberia & 55.43781 Oman & 12242.3 St. Vincent \& Grenadines & 4684.312 \\
\hline Andorra & 38704.75 Chile & 12634.35 Grenada & 6173.605 Libya & 1300.758 Pakistan & 240.0721 Sudan & 894.7908 \\
\hline Angola & 587.9438 China & 4793.058 Guam & 28720.96 Lithuania & 13046.85 Panama & 8793.409 Suriname & 2602.606 \\
\hline Antigua and Barbuda & 11250.29 Colombia & 3990.186 Guatemala & 1819.829 Luxembourg & 102228.6 Papua New Guinea & 278.9857 Sweden & 51341.49 \\
\hline Argentina & 10915.36 Comoros & 111.2619 Guinea & 93.87845 Macao & 67281.87 Paraguay & 3556.909 Switzerland & 75292.39 \\
\hline Armenia & 2744.662 Congo, Dem. Rep. & 39.89116 Guinea-Bissau & 28.44153 Madagascar & 44.07279 Peru & 3202.345 Tajikistan & 175.9108 \\
\hline Aruba & 24929.06 Congo, Rep. & 143.0719 Guyana & 1737.572 Malawi & 46.65048 Philippines & 1795.008 Tanzania & 153.3513 \\
\hline Australia & 46555.47 Costa Rica & 8358.784 Haiti & 94.37899 Malaysia & 7975.215 Poland & 10534.27 Thailand & 3488.225 \\
\hline Austria & 41664.61 Cote dflvoire & 674.0406 Honduras & 797.0223 Maldives & 7045.877 Portugal & 15711.21 Timor-Leste & 626.629 \\
\hline Azerbaijan & 3266.759 Croatia & 8981.84 Hong Kong & 41304.46 Mali & 105.2005 Qatar & 60681.5 Togo & 75.41613 \\
\hline Bahamas, The & 26147.71 Cuba & 4141.044 Hungary & 10959.11 Malta & 21417.66 Romania & 6896.974 Tonga & 1633.07 \\
\hline Bahrain & 22760.66 Cyprus & 20717.73 Iceland & 70070.96 Marshall Islands & 1487.332 Russian Federation & 8170.157 Trinidad and Tobago & 12469.89 \\
\hline Bangladesh & 273.2757 Czech Republic & 16042.89 India & 681.891 Mauritania & 236.458 Rwanda & 162.8855 Tunisia & 1922.751 \\
\hline Barbados & 13373.59 Denmark & 55559.14 Indonesia & 1242.102 Mauritius & 5828.178 Samoa & 1438.83 Turkey & 6821.738 \\
\hline Belarus & 4267.67 Djibouti & $1073.309 \operatorname{Iran}$ & 3379.603 Mexico & 5689.448 San Marino & 29421.94 Turkmenistan & 1399.724 \\
\hline Belgium & 38112.12 Dominica & 4677.98 Iraq & 2476.869 Micronesia & 1125.337 Sao Tome \& Principe & 575.0641 Tuvalu & 1750.789 \\
\hline Belize & 2340.572 Dominican Republic & 4583.489 Ireland & 58218.81 Moldova & 1743.431 Saudi Arabia & 17121.44 Uganda & 143.7726 \\
\hline Benin & 116.8198 Ecuador & 3592.968 Israel & 33075.94 Mongolia & 881.5715 Senegal & 394.0473 Ukraine & 1507.739 \\
\hline Bhutan & 1505.843 Egypt, Arab Rep. & 1084.526 Italy & 19683.81 Montenegro & 5547.885 Serbia & 4150.379 United Arab Emirates & 38590.62 \\
\hline Bolivia & 1487.648 El Salvador & 1215.462 Jamaica & 2494.679 Morocco & 1867.027 Seychelles & 9185.314 United Kingdom & 37804.07 \\
\hline Bosnia Herzegovina & 3577.549 Equatorial Guinea & 2544.658 Japan & 34922.77 Mozambique & 88.54335 Sierra Leone & 66.12232 United States & 45085.37 \\
\hline Botswana & 3145.631 Estonia & 17797.03 Jordan & 2758.274 Myanmar & 385.5207 Singapore & 48739.46 Uruguay & 11092.44 \\
\hline Brazil & 6620.344 Eswatini & 982.5536 Kazakhstan & 6901.579 Namibia & 1926.881 Slovak Republic & 14349.19 Uzbekistan & 802.2829 \\
\hline Brunei Darussalam & 26838.34 Ethiopia & 142.9054 Kenya & 284.3128 Nauru & 5041.503 Slovenia & 18618.07 Vanuatu & 803.387 \\
\hline Bulgaria & 5217.39 Fiji & 2792.815 Kiribati & $232.4769 \mathrm{Nepal}$ & 181.7182 Solomon Islands & 254.2383 Vietnam & 1161.029 \\
\hline Burkina Faso & 101.9311 Finland & 40064.84 Korea, Rep. & 28284.59 Netherlands & 45184.62 Somalia & 9.58625 West Bank and Gaza & 2017.761 \\
\hline Burundi & 16.33673 France & 30979.77 Kuwait & 28459.55 New Zealand & 38670.16 South Africa & 3454.9 Yemen, Rep. & 295.7198 \\
\hline Cabo Verde & 1854.574 Gabon & 3730.631 Kyrgyz Republic & 466.2091 Nicaragua & 619.0628 South Asia & 564.5605 Zambia & 421.4865 \\
\hline Cambodia & 470.7039 Gambia & 140.6558 Lao PDR & 626.8877 Niger & 38.65396 Spain & 23864.86 Zimbabwe & 360.7567 \\
\hline Cameroon & 336.876 Georgia & 2447.125 Latvia & 12754.03 Nigeria & 544.8796 Sri Lanka & 1389.688 & \\
\hline
\end{tabular}

